\title{
Safety of Cyclooxygenase-2 Inhibitors in Osteoarthritis: Outcomes of a Systematic Review and Meta-Analysis
}

\author{
Elizabeth Curtis ${ }^{1}$ (D) . Nicholas Fuggle ${ }^{1}$. Sarah Shaw ${ }^{1} \cdot$ Laura Spooner $^{2} \cdot$ Georgia Ntani $^{1} \cdot$ Camille Parsons $^{1}$. \\ Nadia Corp ${ }^{3}$. Germain Honvo ${ }^{4,5}$. Janis Baird ${ }^{1}$. Stefania Maggi ${ }^{6}$. Elaine Dennison ${ }^{1}$. Olivier Bruyère ${ }^{4,5}$. \\ Jean-Yves Reginster ${ }^{4,5,7}$ (i) Cyrus Cooper ${ }^{1,5,8}$ (])
}

(๑) The Author(s) 2019

\begin{abstract}
Objective Our aim was to assess the safety of cyclooxygenase-2 (COX-2) inhibitors in the management of osteoarthritis $(\mathrm{OA})$ in a systematic review and meta-analysis of randomized, placebo-controlled trials.

Methods A comprehensive literature search was undertaken in the databases MEDLINE, Cochrane Central Register of Controlled Trials (Ovid CENTRAL) and Scopus. Randomized, double-blind, placebo-controlled, parallel-group trials that assessed adverse events (AEs) with COX-2 inhibitors in patients with OA were eligible for inclusion. Two authors appraised titles, abstracts and full-text papers for suitability and then assessed the studies for random sequence generation, allocation concealment, blinding of participants and personnel, blinding of outcome assessment, incomplete outcome data and selective outcomes reporting. The primary outcomes of interest were gastrointestinal disorders, cardiac disorders, vascular disorders, nervous system disorders, skin and subcutaneous tissue disorders, hepatobiliary disorders, renal and urinary disorders, as well as overall severe and serious AEs, drug-related AEs and mortality. Secondary outcomes were withdrawals due to AEs (i.e. the number of participants who stopped the treatment due to an $\mathrm{AE}$ ) and total number of AEs (i.e. the number of patients who experienced any $\mathrm{AE}$ at least once).

Results Database searches identified 2149 records from which, after exclusions, 40 trials were included in the meta-analysis. The use of COX-2 inhibitors in OA was associated with a significant increased risk of drug-related AEs compared with placebo (relative risk (RR) 1.26, 95\% CI 1.09-1.46; $I^{2}=24 \%$ ). The risk of upper gastrointestinal complications (including dyspepsia, gastritis and heartburn) was significantly increased with COX-2 inhibitors versus placebo (RR 1.19, 95\% CI $1.03-1.38 ; I^{2}=0 \%$ ), particularly for abdominal pain, which increased by $40 \%$ with COX-2 inhibitors (RR $1.40,95 \%$ CI $1.08-1.80 ; I^{2}=0 \%$ ). The risk of hypertension increased by $45 \%$ overall (RR $1.45,95 \%$ CI $1.01-2.10 ; I^{2}=25 \%$ ); however, when rofecoxib was removed from the analysis the risk of hypertension in the COX-2 inhibitor group was no longer significant (RR $1.21,95 \%$ CI $0.80-1.83 ; I^{2}=20 \%$ ). The overall risk of heart failure and edema was increased by nearly $70 \%$ with COX-2 inhibitors versus placebo (RR 1.68, 95\% CI 1.22-2.31;0\%) and this level of risk did not change appreciably when rofecoxib was excluded (RR 1.67, 95\% CI 1.21-2.29; 0\%).

Conclusions In our analysis, COX-2 inhibitors were associated with an increased risk of upper gastrointestinal AEs, especially abdominal pain. We also found an increased risk of cardiovascular AEs with COX-2 inhibitors, namely hypertension, heart failure and edema.
\end{abstract}

Electronic supplementary material The online version of this article (https://doi.org/10.1007/s40266-019-00664-x) contains supplementary material, which is available to authorized users.

Cyrus Cooper

cc@mrc.soton.ac.uk

Extended author information available on the last page of the article

\section{Introduction}

Non-steroidal anti-inflammatory drugs (NSAIDs) inhibit the enzyme cyclooxygenase (COX), which mediates the conversion of arachidonic acid to inflammatory prostaglandins (PGs). COX-1 is constitutively expressed in the gastric epithelium, therefore providing protection to the gastric mucosa as it regulates the production of acid and mucus. COX- 2 is 


\section{Key Points}

Although specifically designed to avoid the gastrointestinal side effects associated with non-selective NSAIDs, our analysis shows that cyclooxygenase-2 (COX-2) inhibitors are associated with an increased risk of upper gastrointestinal adverse events (AEs), especially abdominal pain, when used to treat pain in osteoarthritis (OA).

As expected, COX-2 inhibitors were associated with an increased risk of cardiovascular AEs; the risk of heart failure and edema remained significant even when rofecoxib was removed from the analysis.

These results confirm that a cautious approach to the use of COX-2 inhibitors (as for other NSAIDs) for the symptomatic management of pain and inflammation in $\mathrm{OA}$ is advisable, limiting use to intermittent or cyclical use rather than chronic treatment in order to minimize safety concerns.

involved in inflammation and is a source of the inflammatory mediators prostaglandin $\mathrm{E}_{2}\left(\mathrm{PGE}_{2}\right)$ and prostacyclin $\left(\mathrm{PGI}_{2}\right)$ via the arachidonic acid pathway [1]. COX-2 inhibitors are a subclass of NSAIDs that were designed to selectively interrupt the production of inflammatory mediators without compromising gastric epithelial function [2]. COX-2 inhibitors are indicated for anti-inflammatory, anti-pyretic and analgesic effects in disorders such as osteoarthritis (OA), rheumatoid arthritis (RA) and acute pain.

There are few COX-2 inhibitors in current clinical use: celecoxib (200 mg/day, oral), etoricoxib [60 mg/day, oral; although not approved by the US Food and Drug Administration (FDA)] and parecoxib (80 mg/day, intravenous or intramuscular injection for postoperative pain; not approved by the FDA). Further, the FDA and European Medicines Agency (EMA) have withdrawn approval for other COX-2 inhibitors due to an increased risk of cardiovascular adverse events (AEs); rofecoxib was withdrawn in 2004 due to thrombotic cardiovascular events observed in a randomized controlled trial (RCT) [3]; valdecoxib was withdrawn in 2005 due to skin reactions and cardiovascular events postcoronary artery bypass graft surgery in two RCTs [4, 5]; and lumiracoxib was withdrawn by the EMA in 2007 due to liver toxicity and skin reactions [6], and did not gain full FDA approval.

The proposed mechanism for an increase in occurrence of cardiovascular events is an imbalance between prostacyclin and thromboxane $\mathrm{A}_{2}\left(\mathrm{TXA}_{2}\right)$, with prostacyclin production decreased but TXA 2 continuing, leading to platelet activation, vascular proliferation, vascular contraction and cell adhesion, which may occur within the coronary arteries.
COX-2 inhibition leads to reduced $\mathrm{PGI}_{2}$ from the vascular endothelium; thus, the protective effect of $\mathrm{PGI}_{2}$ is lost, which predisposes to injury, cell adhesion and vessel contraction. TXA $_{2}$ production by platelets is not inhibited by COX-2 inhibitors, which leads to platelet activation and a prothrombotic state (Fig. 1) [7].

There are meta-analyses comparing the relative safety of COX-2 inhibitors with non-selective NSAIDs [8-14]. However, the objective of this study was to assess the safety of oral COX-2 inhibitors in the management of OA in a systematic review and meta-analysis of randomized, placebocontrolled trials.

\section{Methods}

The protocol of this systematic review and meta-analysis was previously registered in the PROSPERO database (registration number: CRD42017068278). The systematic review was performed in accordance with the recommendations in the Cochrane Handbook for Systematic Reviews of Interventions [15]. The findings were reported according to the Preferred Reporting Items for Systematic Reviews and Meta-Analyses (PRISMA) guidelines [16]. All the review process (study selection and risk of bias assessment) was undertaken using Covidence, the Cochrane platform for systematic reviews, and was performed by EC, NF, SS and LS.

\subsection{Eligibility Criteria}

Randomized, double-blind, placebo-controlled, parallel-group trials that have assessed the AEs associated with COX-2 inhibitors (celecoxib, rofecoxib, etoricoxib,

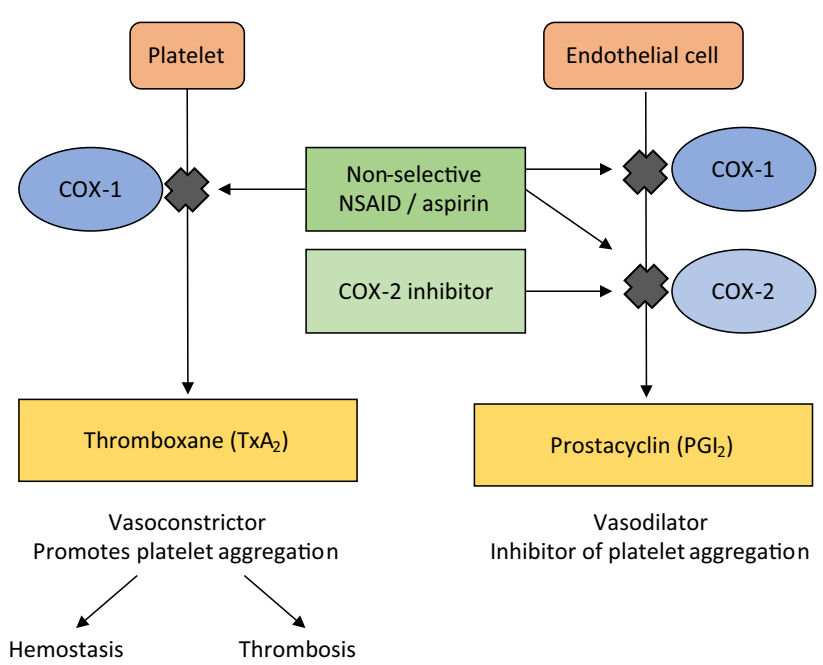

Fig. 1 Effect of cyclooxygenase (COX) inhibition on platelets and endothelium. NSAID non-steroidal anti-inflammatory drug 
valdecoxib but not lumiracoxib as it never gained full FDA approval) in patients with OA were eligible for inclusion in this meta-analysis.

Studies that allowed concomitant anti-osteoarthritis treatments during the trial (other than rescue medication as acetaminophen or aspirin) were also excluded, as were animal trials.

\subsection{Data Sources and Search Strategies}

A comprehensive literature search was undertaken in the following databases: MEDLINE (via Ovid), Cochrane Central Register of Controlled Trials (Ovid CENTRAL) and Scopus. Each database was searched from inception up to 30 June 2017. We searched for randomized placebo-controlled trials of COX-2 inhibitors in OA, using a combination of study design-, treatment- and disease-specific key words and Medical Subject Heading (MeSH) terms.

While adverse effects were the outcomes of interest for this study, we decided to avoid the outcome-specific key words in the search strategies, because of the possibility that a study on the efficacy of a drug may have not mentioned terms related to adverse events in its title, abstract or in the keyword section. The search was limited to English and French publications and to human subjects. Detailed search strategies for MEDLINE/CENTRAL and Scopus databases are reported as Electronic Supplementary Material (ESM1).

Two clinical trial registries, ClinicalTrials.gov (clinicaltrials.gov/) and the World Health Organization's International Clinical Trials Registry Platform Search portal (apps. who.int/trialsearch/) were also checked for trial results that were unpublished. Finally, recent meta-analyses were also screened for any additional relevant studies.

\subsection{Study Selection}

Two members of the review team independently evaluated each title and abstract to exclude only obvious irrelevant studies, according to the predefined eligibility criteria. At this step, the criteria related to adverse effects was not considered for selection, as studies focusing on the efficacy of a treatment may not report data about adverse effects in the abstract; this means that all trials mentioning only the efficacy information were retrieved at this step. After this first step, the two investigators independently reviewed the full text of each of the articles not excluded during the initial screening stage to determine whether the studies met all selection criteria. At this stage, studies were excluded due to previously unidentified duplication, conference abstracts alone being available, a non-placebo comparator being used alone against COX-2 medication in the trial, an indication other than OA, safety not being included as an outcome of the trial, a non-COX-2 intervention or incorrect study design. All differences of opinion regarding the selection of articles were resolved through discussion and consensus between the two investigators; any persistent disagreement was solved with the intervention of a third person (another member of the review team).

\subsection{Data Extraction}

The full texts of the selected studies were screened by independent reviewers for extraction of relevant data, using a standard data extraction form. Outcome results data were independently extracted by two investigators from the review team. For each study, the following data were extracted: characteristics of the manuscript, characteristics of the trial, objective and design of the study, characteristics of the patients, characteristics of the disease, characteristics of the treatments, AEs (outcomes) reported during the trial and the main conclusion of the study. In the case of multiple dosage arms for COX-2 inhibitors being included in a trial, the maximum dose was used to categorize the study. If multiple follow-up times were included, the longest follow-up time was used to categorize the study. The raw data (number of events in each group) were extracted for each outcome. The number of patients who experienced at least once any body-system-related AE (e.g. nervous system, gastrointestinal system), as well as AEs within each body system (e.g. headache, abdominal pain) were extracted. As much as possible, data from the intention-to-treat (ITT) analysis were considered.

\subsection{Outcomes of Interest}

The main System Organ Classes (SOCs) that are likely to be affected by the use of COX-2 inhibitors in the treatment of OA were explored in this meta-analysis. The primary outcomes of interest were gastrointestinal disorders, cardiac disorders, vascular disorders, nervous system disorders, skin and subcutaneous tissue disorders, hepatobiliary disorders, renal and urinary disorders, as well as overall severe and serious AEs, drug-related AEs and mortality. Secondary outcomes were withdrawals because of AEs (i.e. the number of participants who stopped the treatment because of an AE) and total number of AEs (i.e. the number of patients who experienced any $\mathrm{AE}$ at least once).

\subsection{Assessment of Risk of Bias in Included Studies}

Two authors of the review team independently assessed the risk of bias in each study using the Cochrane Collaboration's tool for risk of bias assessment [15]. The following characteristics were evaluated: 
- Random sequence generation: we assessed whether the allocation sequence was adequately generated.

- Allocation concealment: we assessed the method used to conceal the allocation sequence, evaluating whether the intervention allocation could have been foreseen in advance.

- Blinding of participants and personnel: we assessed the method used to blind study participants and personnel from knowledge of which intervention a participant received and whether the intended blinding was effective.

- Blinding of outcome assessment: we assessed the method used to blind outcome assessors from knowledge of which intervention a participant received and whether the intended blinding was effective.

- Incomplete outcome data: we assessed whether participants' exclusions, attrition and incomplete outcome data were adequately addressed in the paper.

- Selective outcomes reporting: we checked whether there was evidence of selective reporting of adverse events.

Each of these items was either categorized as 'low risk of bias', 'high risk of bias', or 'unclear risk of bias'. 'Low risk of bias' or 'high risk of bias' was attributed to an item when there was sufficient information in the manuscript to judge the risk of bias as 'low' or 'high'; otherwise, 'unclear risk of bias' was attributed to the item. Disagreements were solved by discussion between the two reviewers during a consensus meeting and involved, when necessary, another member of the review team for the final decision.

\subsection{Data Analysis}

Analyses were performed using STATA 14.2 software. The units of analysis were the number of participants experiencing a specific adverse event. We described harms associated with the treatment as risk ratio with $95 \%$ confidence interval $(95 \% \mathrm{CI})$. We computed an overall effect size for each primary or secondary outcome (AE). Anticipating substantial variability among trial results (i.e. the inter-study variability), we assumed heterogeneity in the occurrence of the AEs; thus, we planned to use random-effects models for the meta-analyses. We estimated the overall effects and heterogeneity using the DerSimonian and Laird random-effects model [17]. As this method provides a biased estimate of the between-study variance with sparse events $[18,19]$, we also performed the meta-analyses using the Restricted Maximum Likelihood (REML) method [20]. As rofecoxib was withdrawn by the FDA and EMA in 2004 due to thrombotic cardiovascular events, we performed a sensitivity analysis for AEs for the COX-2 inhibitor class minus rofecoxib.

We tested heterogeneity using the Cochran's Q test. As we are performing a random-effect meta-analysis, we used the Tau-squared $\left(\tau^{2}\right)$ estimate as the measure of the betweenstudy variance. The I-squared $\left(I^{2}\right)$ statistic was used to quantify heterogeneity, measuring the percentage of total variation across studies due to heterogeneity [21]. The quality of each evidence was assessed using the GRADE approach [22] and a summary of findings table was prepared using GRADEpro online software [23].

\section{Results}

\subsection{Study Selection}

Database searches initially identified 2149 records. After exclusions, 73 articles were screened in full against the inclusion criteria. A flowchart (Fig. 2) with the number of included studies at each step was established, including the reasons for excluding studies during the full-text reading process. Forty-one of these met the eligibility criteria and included a placebo comparator, but a further five were excluded as the specific outcomes of interest to our strategy were not specified. Thirty-six papers were included, which actually comprised 40 trials as four papers presented results from two studies [24-58].

\subsection{Study Characteristics}

Table 1 presents the characteristics of the studies included through the systematic review process. The year of publication of the included studies ranged from 1999 to 2017 and the follow-up time ranged from 6 weeks to 24 months. The number of trials including an arm for each specific COX-2 inhibitor (or two arms if two COX-2 inhibitors were included) were as follows: celecoxib 20 (49\%), etoricoxib $6(15 \%)$, rofecoxib $10(24 \%)$, celecoxib and etoricoxib $4(10 \%)$, celecoxib and rofecoxib $1(2 \%)$. The anatomic regions included per trial are as follows; knee 24 (59\%), hip 2 (5\%), knee or hip $13(32 \%)$, any OA $1(2 \%)$, not specified $1(2 \%)$.

\subsection{Risk of Bias of Individual Studies}

Figures 3 and 4 include a summary of the risk of bias assessed for each study included in the meta-analysis and all our findings were associated with a 'moderate' to 'high' certainty of evidence.

\subsection{Primary Outcomes}

We reported only the results from the DerSimonian and Laird random-effects model, because we found no difference in the effects computed by the two methods. 


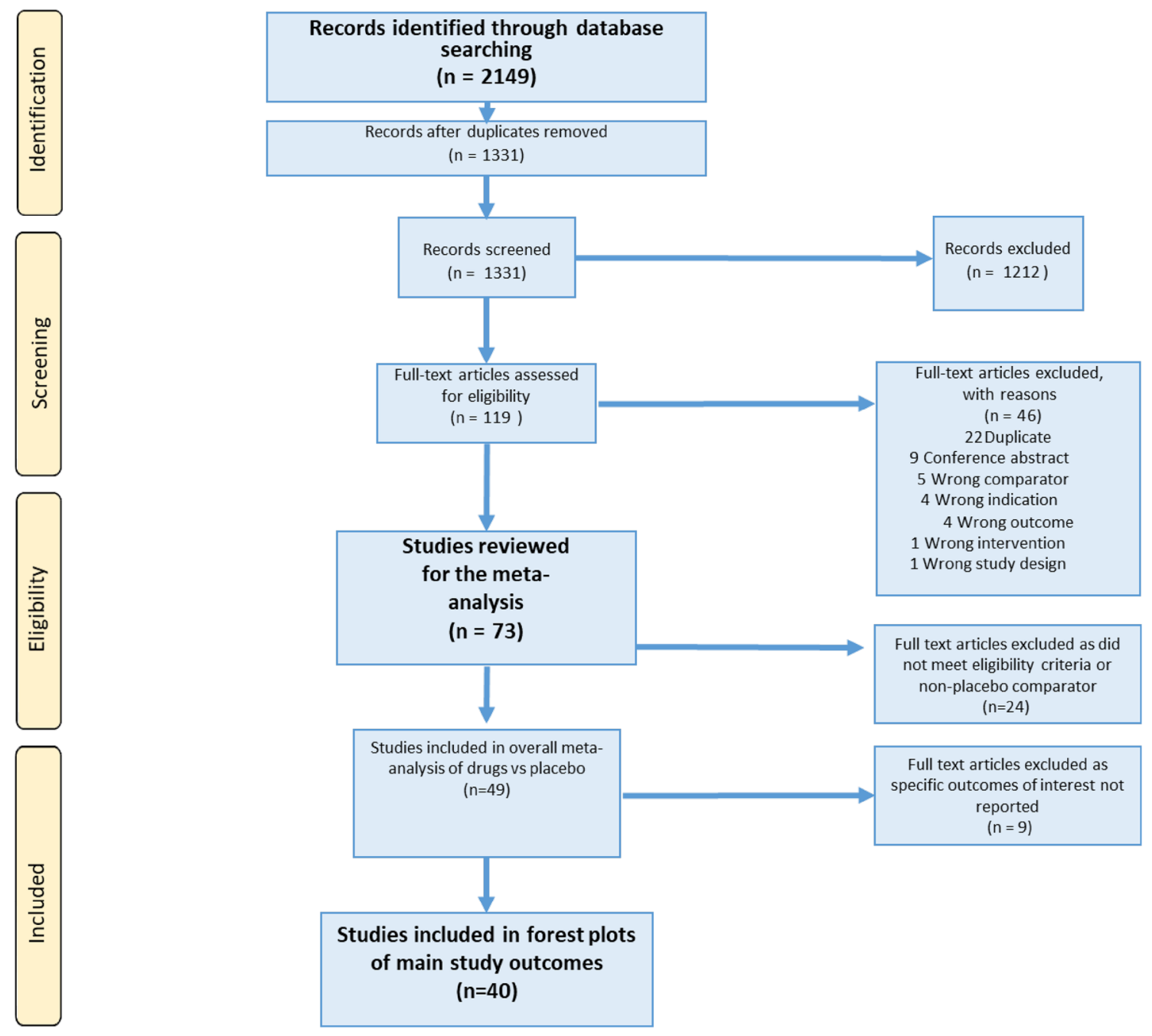

Fig. 2 Flowchart of the study selection process

\subsubsection{Gastrointestinal Complications}

The relative risk of upper gastrointestinal complications overall, including ulcer-related events, dyspepsia and abdominal pain, was significantly increased with COX-2 inhibitors versus placebo (RR 1.19, 95\% CI 1.03-1.38; $I^{2}=0 \%$ ) (Fig. 5). The risk of dyspepsia (RR $1.08,95 \%$ CI $0.90-1.30 ; I^{2}=0 \%$ ) and ulcer-related AEs (RR 2.08, 95\% CI $0.58-7.46 ; I^{2}=0 \%$ ) was not significantly increased in the COX-2 inhibitor group; however, the risk of abdominal pain increased significantly, by $40 \%$, with COX-2 inhibitors (RR $1.40,95 \%$ CI $1.08-1.80 ; I^{2}=0 \%$ ).

There was no increase in the relative risk of nausea and vomiting (RR $0.96,95 \%$ CI $0.75-1.22 ; I^{2}=0 \%$ ) nor any significant difference in the risk of constipation (RR 1.00, 95\% CI $0.58-1.75 ; I^{2}=0 \%$ ) between the COX-2 inhibitors and placebo group (ESM2).

\subsubsection{Cardiovascular Events}

The risk of hypertension increased significantly, by $45 \%$ overall across the 15 studies, including celecoxib, rofecoxib and etoricoxib (RR 1.45, 95\% CI 1.01-2.10; $I^{2}=25 \%$ ) (Fig. 6). However, when rofecoxib was removed from the analysis, the risk of hypertension in the COX-2 inhibitor group was no longer significant (RR 1.21, 95\% CI 0.80-1.83; $\left.I^{2}=20 \%\right)(\mathrm{ESM} 2)$.

The incidence of heart failure (HF)-related events was reported differently across the studies; thus, a grouped analysis was performed. The overall risk of HF and edema was increased with COX-2 inhibitors versus placebo (RR 1.68, 95\% CI 1.22-2.31; 0\%) (Fig. 7). The overall increase in risk of around $70 \%$ was not changed appreciably when rofecoxib studies were excluded (RR 1.67, 95\% CI 1.21-2.29; $0 \%$ for celecoxib and etoricoxib only) (ESM2). 


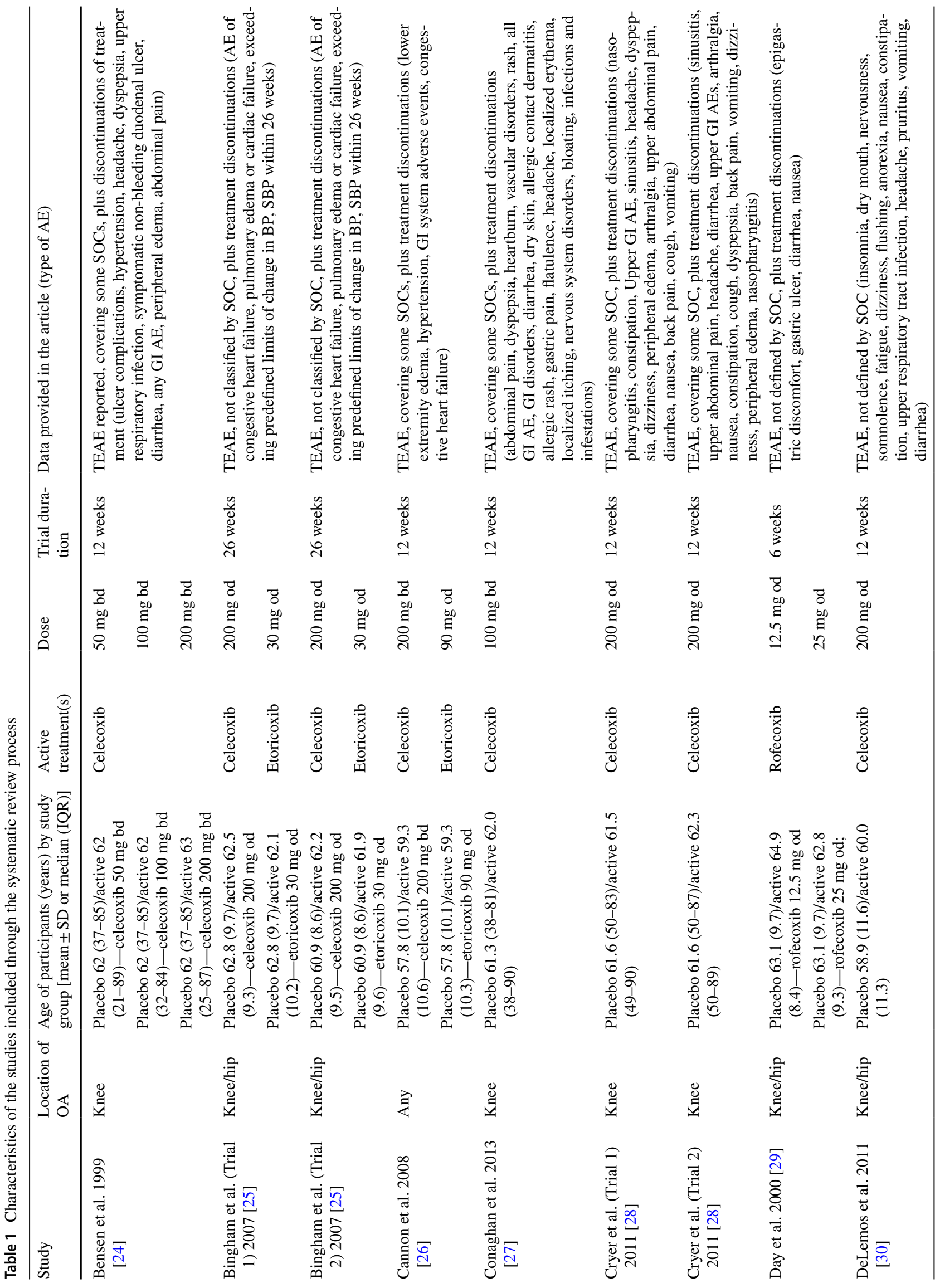




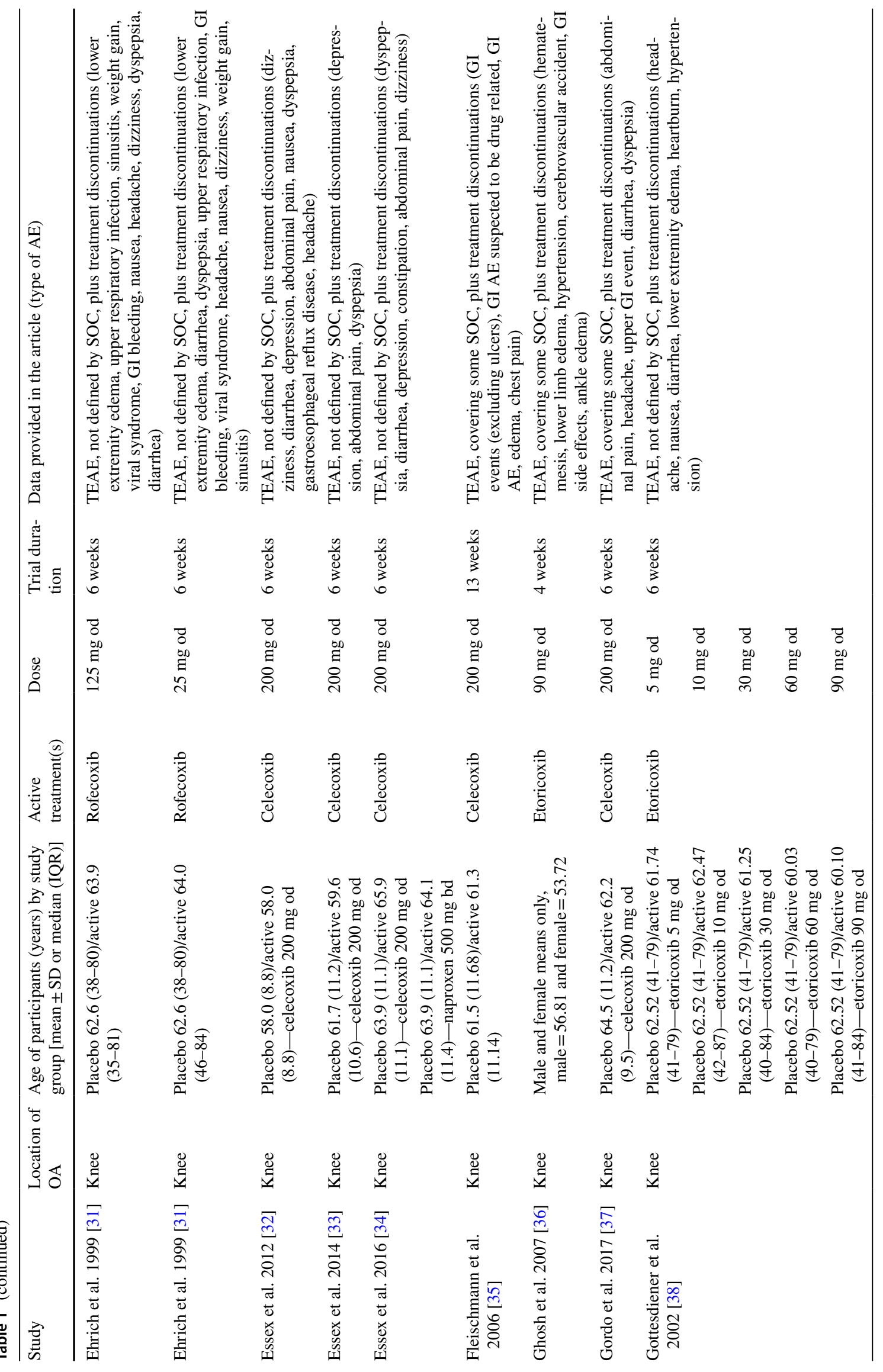




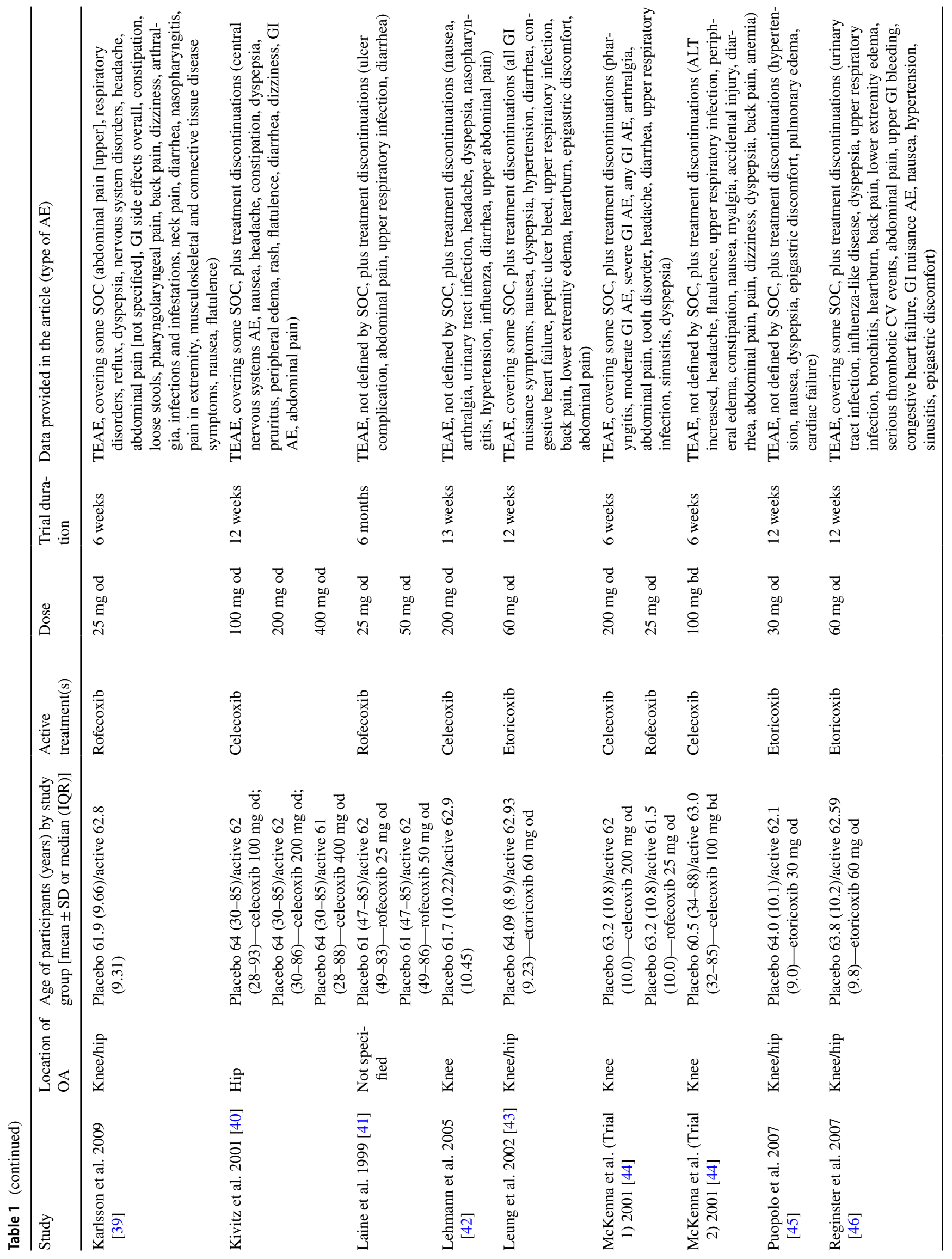




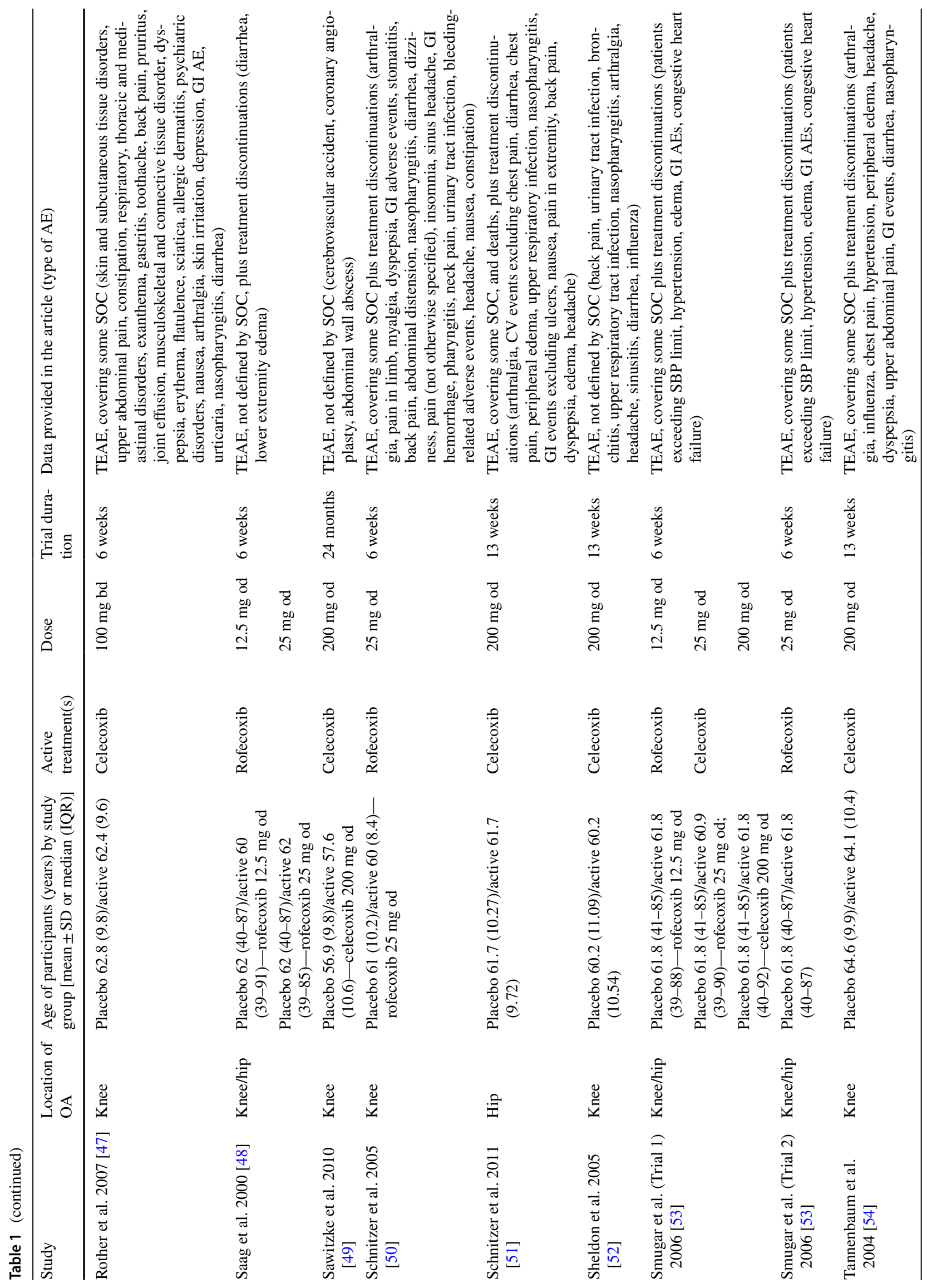




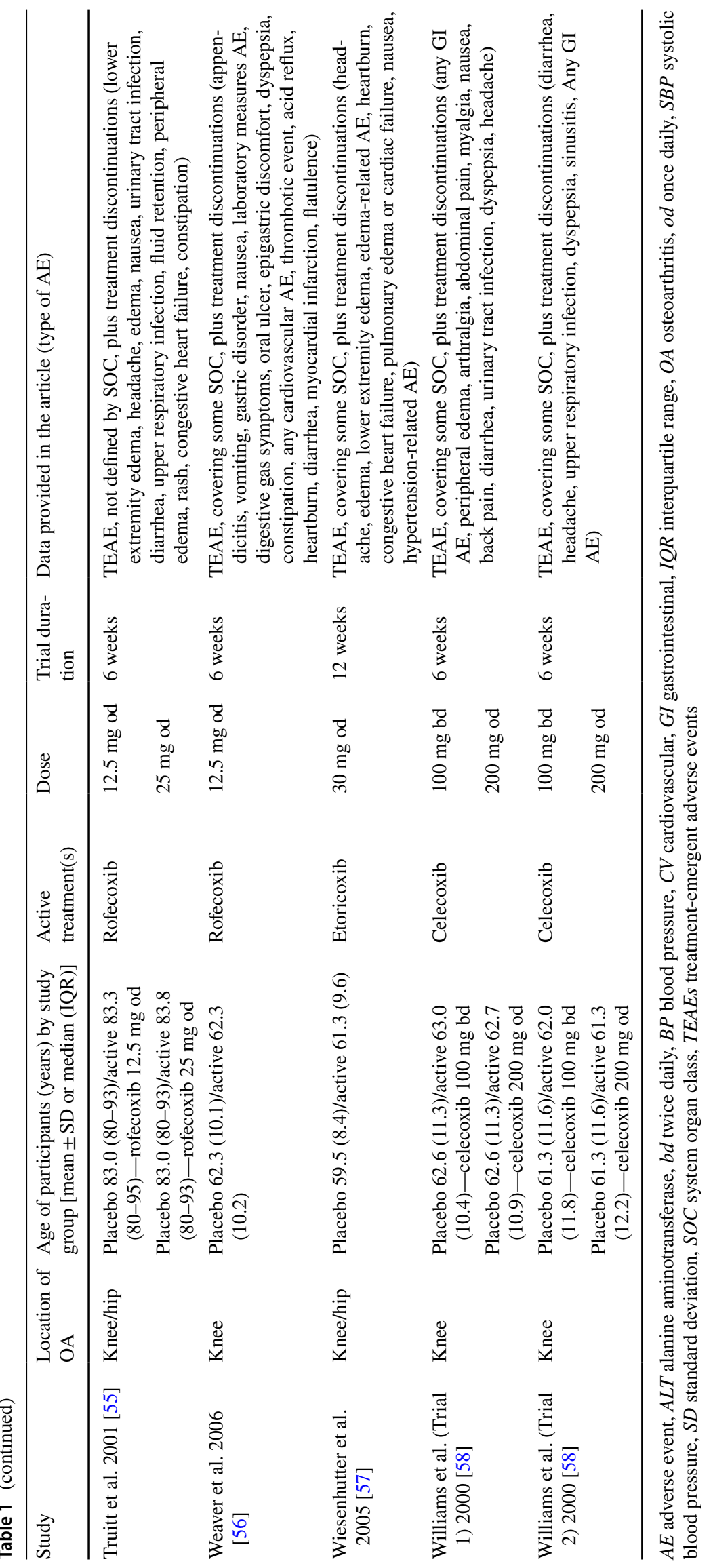




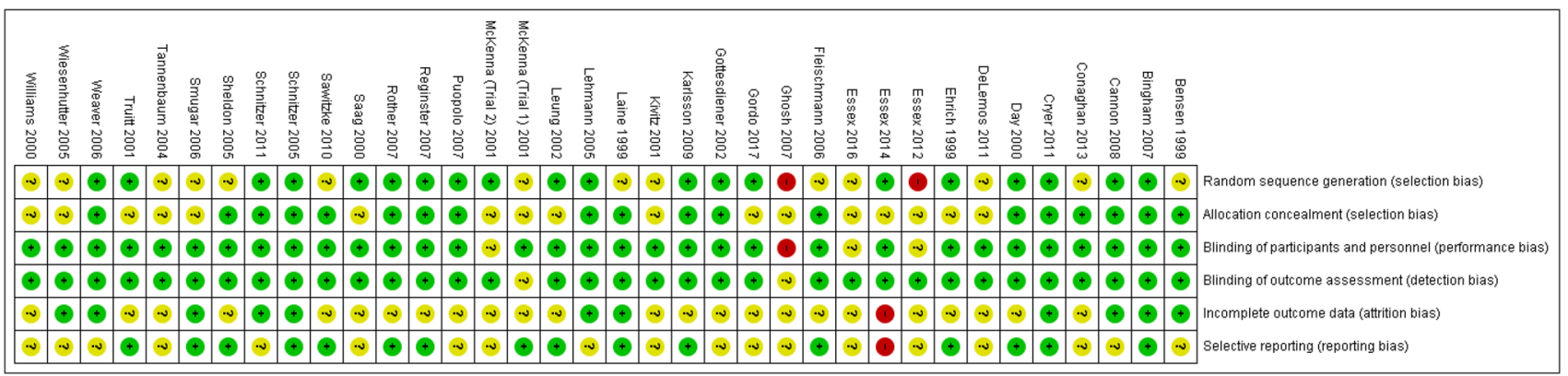

Fig. 3 Risk of bias summary: review of authors' judgements about each risk of bias item for each included study

Random sequence generation (selection bias)

Allocation concealment (selection bias)

Blinding of participants and personnel (performance bias)

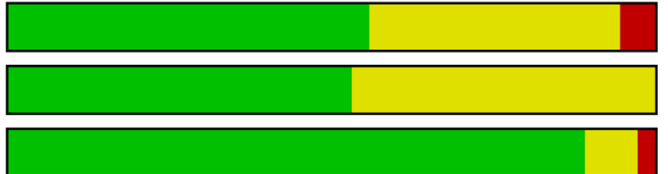

\section{Blinding of outcome assessment (detection bias) \\ Incomplete outcome data (attrition bias) \\ Selective reporting (reporting bias)}

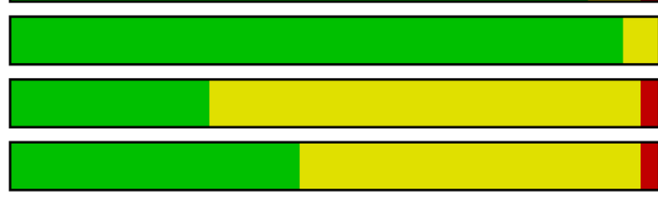

$$
09
$$

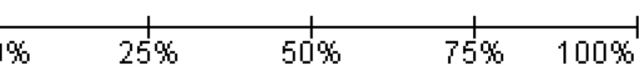

Low risk of bias

Unclear risk of bias

High risk of bias

Fig. 4 Risk of bias graph: review of authors' judgements about each risk of bias item presented as percentages across all included studies

The risk of congestive HF (CHF) was not significantly increased (RR 1.18, 95\% CI 0.24-5.71; $p=0.944 ; I^{2}=0 \%$ ). The risk of peripheral edema was increased by $61 \%$ (RR $1.61,95 \%$ CI $\left.1.09-2.40 ; I^{2}=0 \%\right)$ and the risk of generalized edema increased by $91 \%$ (RR 1.91, 95\% CI 1.08-3.39; $\left.I^{2}=0 \%\right)$.

\subsubsection{Other Primary Outcomes}

Central nervous system (CNS) AEs were grouped into dizziness, headache and other (incorporating insomnia, depression and psychiatric disorders). No appreciable difference in the risk of CNS AEs was observed between the placebo and COX-2 inhibitor groups (RR 0.94, 95\% CI 0.84-1.04; $0 \%)$ (ESM2). Neither was there any increase in the risk of dermatological AEs (rash or pruritis) (RR 1.02, 95\% CI 0.76-1.37; 0\%) (ESM2). Too few studies reported on renal and hepatic AEs and mortality for these to be included in the meta-analysis.

The risk of drug-related AEs was significantly increased with COX-2 inhibitors versus placebo ( $R R=1.26,95 \%$ CI $1.09-1.46 ; I^{2}=24 \%$ ) (Fig. 8). There was no significant difference in risk of serious AEs (SAEs) with COX-2 inhibitors versus placebo, although a lower rate of SAEs was recorded (RR 0.76, 95\% CI 0.48-1.19; $I^{2}=21 \%$ ) (ESM2).

\subsection{Secondary Outcomes}

Overall, there was no increase in total risk of AEs between the COX-2 inhibitor group and the placebo group, even with the highest dose of COX-2 inhibitor included in the analysis (RR $1.03,95 \%$ CI $0.97-1.10 ; I^{2}=66 \%$ ) (ESM2). Too few studies reported on withdrawals due to AEs for this to be included in the meta-analysis.

\subsection{GRADE Assessment of Findings}

We assessed the certainty of evidence for each primary or secondary outcome for COX-2 inhibitors compared with placebo, using the GRADE approach [22]. Our findings were associated with 'moderate' to 'high' certainty of evidence. Table 2 summarizes the significant findings while Table 3 summarizes the non-significant findings for the safety outcomes assessed in this meta-analysis. 


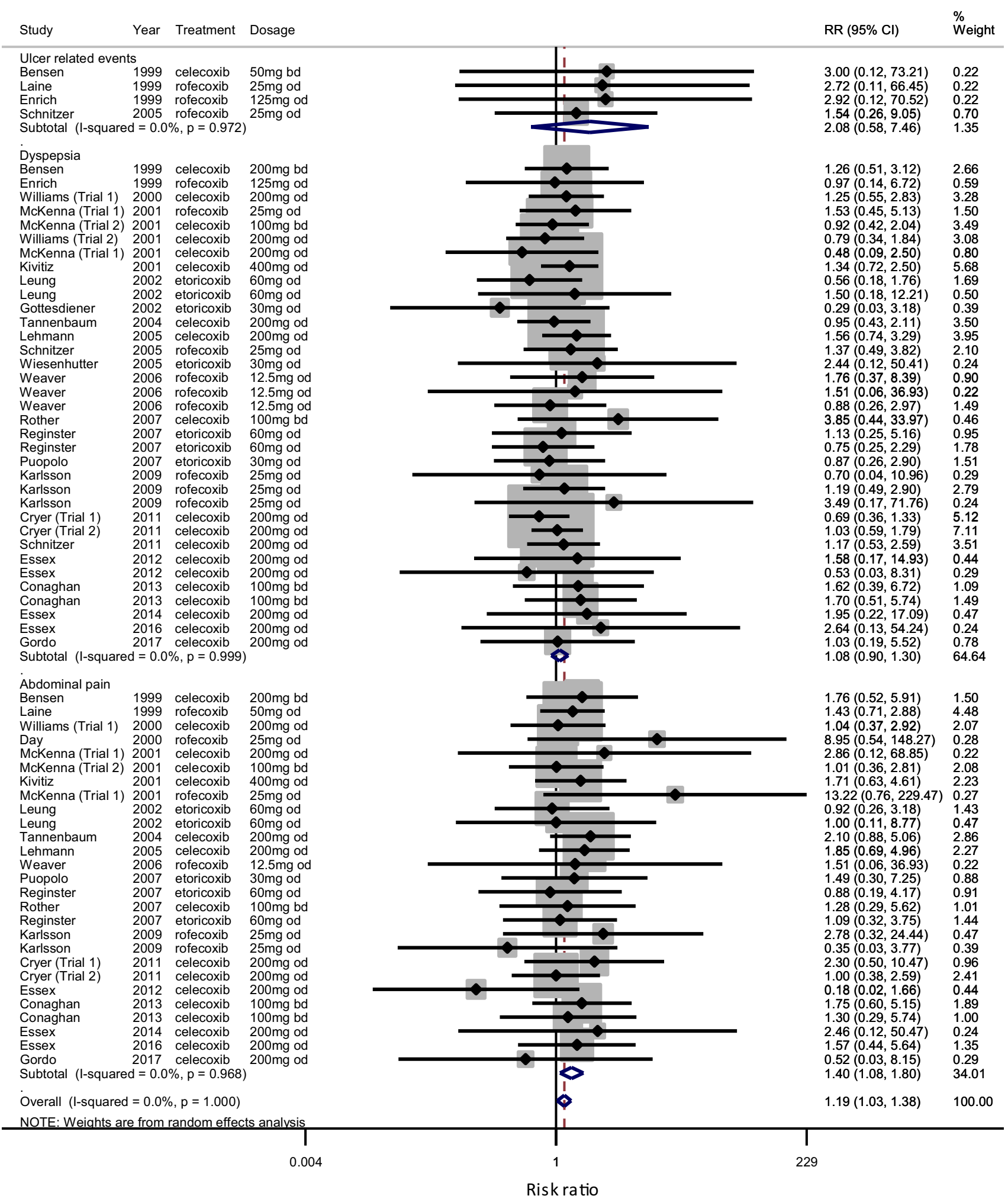

Fig. 5 Relative risk of upper gastrointestinal adverse events (ulcer-related events, dyspepsia, abdominal pain) for COX-2 inhibitors versus placebo. $C I$ confidence interval, $C O X-2$ cyclooxygenase-2, $R R$ relative risk 


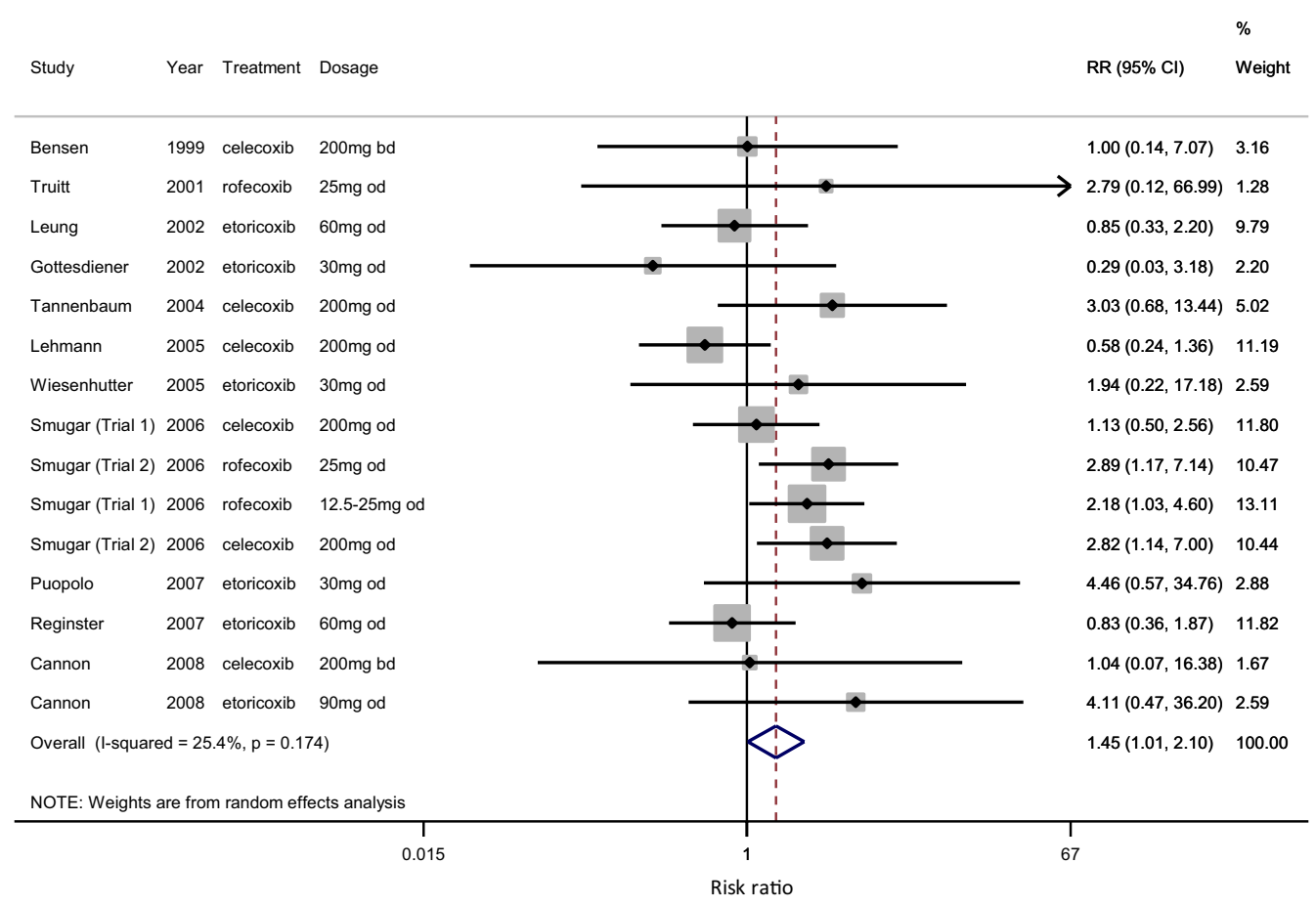

Fig. 6 Relative risk of hypertension adverse events for COX-2 inhibitors versus placebo. $C I$ confidence interval, $C O X-2$ cyclooxygenase-2, $R R$ relative risk

\section{Discussion}

Overall, our analysis found a significant increased risk of drug-related AEs with COX-2 inhibitors compared with placebo. While it is widely accepted that NSAIDs with COX-2 selectivity are associated with less gastrointestinal toxicity compared with non-selective NSAIDs, nonetheless, our study found a 19\% increase in upper gastrointestinal AEs overall with COX-2 inhibitors compared with placebo, and a $40 \%$ increase in risk of abdominal pain. This finding is in line with another recent meta-analysis from Bhala et al., that found an increase in upper gastrointestinal complications with COX-2 inhibitors, albeit a lower risk than that with the non-selective NSAIDs ibuprofen and naproxen, but similar to the risk with diclofenac [11]. A retrospective pooled analysis of 21 RCTs of 9461 patients aged $\geq 65$ years with OA, rheumatoid arthritis or ankylosing spondylitis that examined the incidence of gastrointestinal AEs (abdominal pain, constipation, diarrhea, dyspepsia, flatulence, nausea) with celecoxib versus non-selective NSAIDs found a significantly lower incidence of gastrointestinal intolerability reported with celecoxib than naproxen, ibuprofen or diclofenac $(p<0.001)$ [59].

As may be expected with COX-2 inhibitors, we found a significant increase in cardiovascular AEs; specifically, a $45 \%$ increased risk of hypertension that decreased to $21 \%$ when rofecoxib was excluded from the analysis. Nonselective
NSAIDs and COX-2 selective inhibitors increase blood pressure in both normotensive subjects as well as in patients with hypertension. The mechanism for the increase in blood pressure is most likely due to their impact on vasoactive endothelium-derived factors, particularly via the inhibition of prostaglandin synthesis, important for the regulation of vascular tone and sodium excretion [60]. The comparative effect of rofecoxib, celecoxib and naproxen on ambulatory blood pressure has been studied in 400 patients with arterial hypertension, diabetes mellitus and OA. Rofecoxib, but not celecoxib and naproxen, significantly increased 24-hour systolic blood pressure after 6 weeks of therapy [61].

Elevated arterial hypertension is a major risk factor for stroke, ischemic heart disease and HF [62]. We found a $68 \%$ overall increase in risk of CHF and edema (peripheral and generalized) with COX-2 inhibitors, which was not reduced when rofecoxib was excluded from the analysis. A systematic review and meta-analysis assessed the risk of developing incident HF with the use of NSAIDs for any indication, finding a higher risk of developing HF with NSAIDs, which was significantly elevated with non-selective NSAIDs, but not with COX-2 inhibitors [63]. The rates of hospital admission for CHF with rofecoxib, celecoxib and NSAIDs have been compared in 150,000 individuals aged $\geq 65$ years. Users of rofecoxib and NSAIDs, but not celecoxib, were associated with a higher incidence of admission than non-NSAIDs users [64]. 


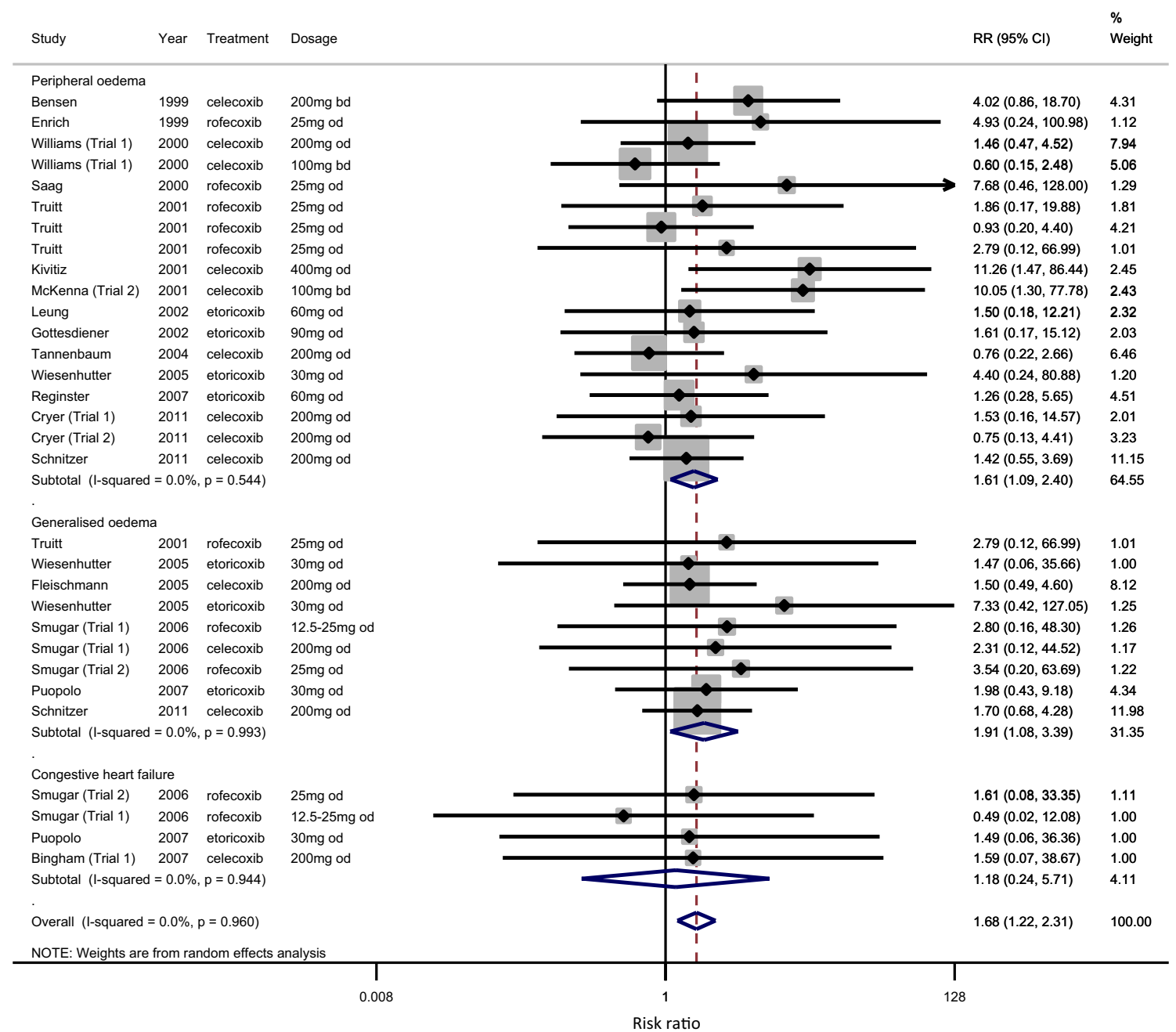

Fig. 7 Relative risk of edema (peripheral and generalized) and heart failure adverse events for COX-2 inhibitors versus placebo. $C I$ confidence interval, $C O X-2$ cyclooxygenase- $2, R R$ relative risk

In the Prospective Randomized Evaluation of Celecoxib Integrated Safety vs Ibuprofen Or Naproxen (PRECISION) trial, celecoxib was found to be non-inferior to naproxen or ibuprofen for the primary composite outcome of cardiovascular death (including hemorrhagic death), nonfatal myocardial infarction or nonfatal stroke [65]. In a subgroup analysis of OA patients, fewer major cardiovascular AEs were observed in patients treated with celecoxib compared with ibuprofen [66]. This confirms the findings of a Japanese prospective observational study of 10,529 patients with OA or RA prescribed celecoxib or an NSAID, in which celecoxib was not shown to be associated with increased cardiovascular risk in comparison with NSAIDs [67].

We found no significant increase in the risk of total AEs or serious AEs with the use of COX-2 inhibitors (Table 3). Neither was there an increase in the rate of constipation, nausea and vomiting, CNS AEs or dermatological AEs with COX-2 inhibitors versus placebo. Insufficient data on renal and hepatic events or death, or withdrawals due to AEs were reported to include in this meta-analysis.

\subsection{Limitations}

Around half of the studies identified from the literature search that met the inclusion criteria did not provide $\mathrm{AE}$ data suitable for inclusion in the meta-analysis. Included studies were of short duration, that is, $75 \%$ of studies were between 2 and 26 weeks' duration. Many studies lacked detail on how AEs were collected, with many relying on patient selfreporting. The grouping of AEs could have led to lack of resolution, and possible double counting. In combining different drugs and doses into one meta-analysis, we chose the highest dose when multiple doses were presented in a trial, which could have led to an exaggeration of AEs. Sensitivity analysis of the two approaches (highest dose vs multiple dose) revealed only marginal differences in the magnitude 


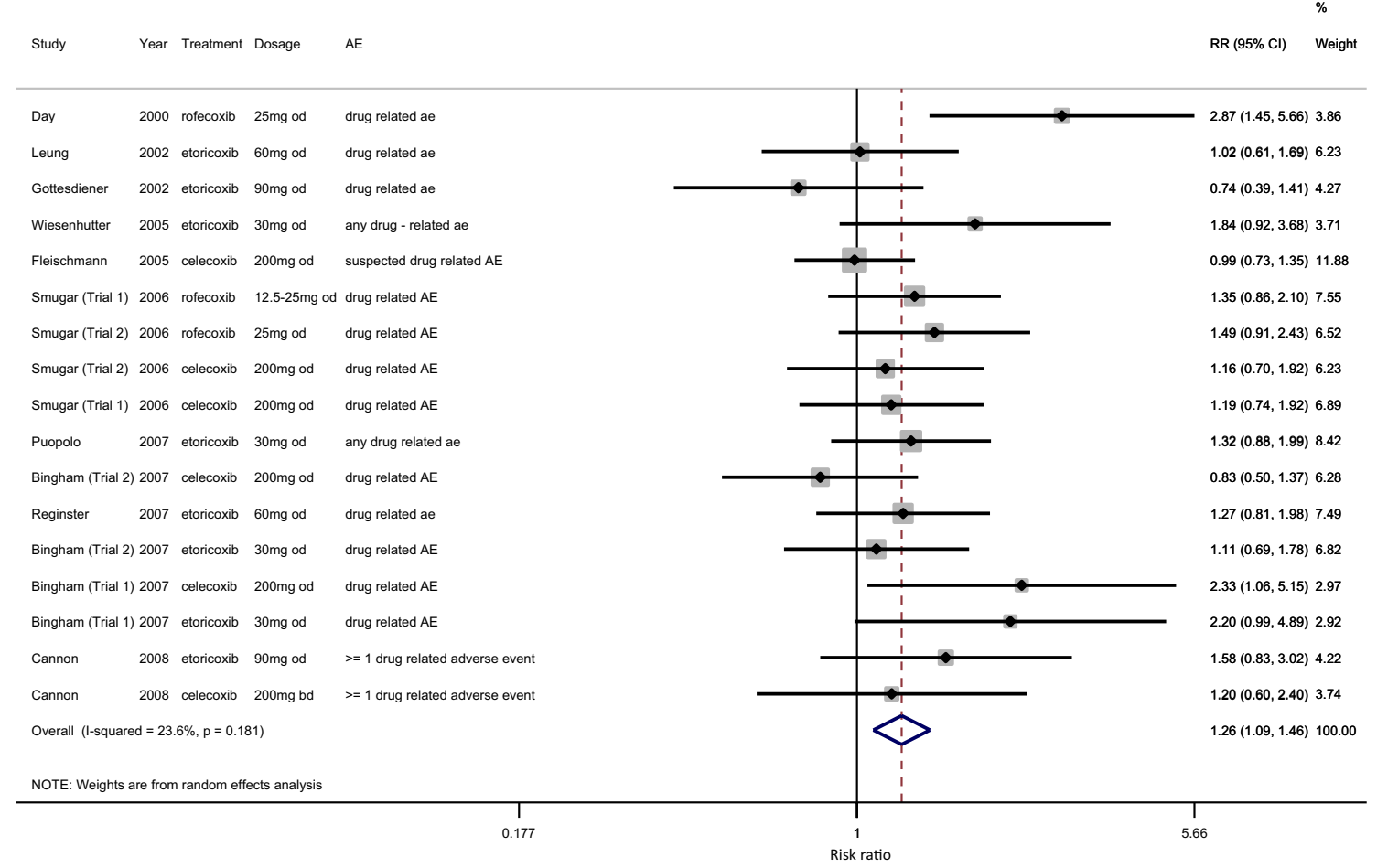

Fig. 8 Relative risk of drug-related adverse events for COX-2 inhibitors versus placebo. AE adverse event, $C I$ confidence interval, $C O X-2$ cyclooxygenase- $2, R R$ relative risk

Table 2 Summary of significant safety findings for COX-2 inhibitors versus placebo in patients with osteoarthritis

\begin{tabular}{|c|c|c|c|c|c|}
\hline \multirow[t]{2}{*}{ Outcomes } & \multirow{2}{*}{$\begin{array}{l}\text { No. of } \\
\text { partici- } \\
\text { pants } \\
\text { Follow- } \\
\text { up }\end{array}$} & \multirow{2}{*}{$\begin{array}{l}\text { Certainty of } \\
\text { the evidence } \\
\text { (GRADE) }\end{array}$} & \multirow{2}{*}{$\begin{array}{l}\text { Relative effect }(95 \% \mathrm{CI}) \\
\text { Risk ratio }\end{array}$} & \multicolumn{2}{|c|}{ Anticipated absolute effects } \\
\hline & & & & Risk with placebo & $\begin{array}{l}\text { Risk difference with COX-2 } \\
\text { inhibitors }\end{array}$ \\
\hline $\begin{array}{l}\text { Treatment-related adverse } \\
\text { events }\end{array}$ & 7463 & $\begin{array}{l}\oplus \oplus \oplus \oplus \\
\mathrm{HIGH}\end{array}$ & $1.26(1.09-1.46)$ & 144 per 1000 & $\begin{array}{l}37 \text { more per } 1000 \text { ( } 13 \text { more to } \\
66 \text { more) }\end{array}$ \\
\hline $\begin{array}{l}\text { Upper gastrointestinal adverse } \\
\text { events overall }\end{array}$ & 23,974 & $\begin{array}{l}\oplus \oplus \oplus \oplus \\
\mathrm{HIGH}\end{array}$ & $1.19(1.03-1.38)$ & 29 per 1000 & $\begin{array}{l}5 \text { more per } 1000 \text { ( } 1 \text { more to } 11 \\
\text { more) }\end{array}$ \\
\hline Abdominal pain & 9907 & $\begin{array}{l}\oplus \oplus \oplus \oplus \\
\mathrm{HIGH}\end{array}$ & $1.40(1.08-1.80)$ & 23 per 1000 & $\begin{array}{l}9 \text { more per } 1000 \text { ( } 2 \text { more to } 19 \\
\text { more) }\end{array}$ \\
\hline Hypertension & 7360 & $\begin{array}{l}\oplus \oplus \oplus \oplus \\
\mathrm{HIGH}\end{array}$ & $1.45(1.01-2.10)$ & 27 per 1000 & $\begin{array}{l}12 \text { more per } 1000 \text { ( } 0 \text { fewer to } 30 \\
\text { more) }\end{array}$ \\
\hline Heart failure and edema & 14,111 & $\begin{array}{l}\oplus \oplus \oplus \oplus \\
\mathrm{HIGH}\end{array}$ & $1.68(1.22-2.31)$ & 10 per 1000 & $\begin{array}{l}7 \text { more per } 1000 \text { ( } 2 \text { more to } 14 \\
\text { more) }\end{array}$ \\
\hline
\end{tabular}

GRADE Working Group grades of evidence: High certainty we are very confident that the true effect lies close to that of the estimate of the effect; Moderate certainty we are moderately confident in the effect estimate: the true effect is likely to be close to the estimate of the effect, but there is a possibility that it is substantially different; Low certainty our confidence in the effect estimate is limited: the true effect may be substantially different from the estimate of the effect; Very low certainty we have very little confidence in the effect estimate: the true effect is likely to be substantially different from the estimate of effect

The risk in the intervention group (and its $95 \% \mathrm{CI}$ ) is based on the assumed risk in the comparison group and the relative effect of the intervention (and its $95 \% \mathrm{CI}$ )

CI confidence interval, $C O X-2$ cyclooxygenase-2 
Table 3 Summary of non-significant safety findings for COX-2 inhibitors versus placebo in patients with osteoarthritis

\begin{tabular}{|c|c|c|c|c|c|}
\hline \multirow[t]{2}{*}{ Outcomes $^{\mathrm{a}}$} & \multirow{2}{*}{$\begin{array}{l}\text { No. of } \\
\text { partici- } \\
\text { pants } \\
\text { Follow- } \\
\text { up }\end{array}$} & \multirow{2}{*}{$\begin{array}{l}\text { Certainty of } \\
\text { the evidence } \\
\text { (GRADE) }\end{array}$} & \multirow{2}{*}{$\begin{array}{l}\text { Relative effect }(95 \% \mathrm{CI}) \\
\text { Risk Ratio }\end{array}$} & \multicolumn{2}{|c|}{ Anticipated absolute effects } \\
\hline & & & & Risk with placebo & $\begin{array}{l}\text { Risk difference with COX-2 } \\
\text { inhibitors }\end{array}$ \\
\hline Total adverse events & 14,908 & $\begin{array}{l}\oplus \oplus \oplus \bigcirc \\
\text { MODERATE }^{b}\end{array}$ & $1.03(0.97-1.10)$ & 471 per 1000 & $\begin{array}{l}14 \text { more per } 1000 \text { ( } 14 \text { fewer to } \\
47 \text { more) }\end{array}$ \\
\hline Serious adverse events & 10,393 & $\begin{array}{l}\oplus \oplus \oplus \oplus \\
\mathrm{HIGH}\end{array}$ & $0.76(0.48-1.19)$ & 18 per 1000 & $\begin{array}{l}4 \text { fewer per } 1000 \text { ( } 9 \text { fewer to } 3 \\
\text { more) }\end{array}$ \\
\hline Constipation & 3066 & $\begin{array}{l}\oplus \oplus \oplus \oplus \\
\mathrm{HIGH}\end{array}$ & $1.00(0.58-1.75)$ & 16 per 1000 & $\begin{array}{l}0 \text { fewer per } 1000 \text { ( } 7 \text { fewer to } 12 \\
\text { more) }\end{array}$ \\
\hline Nausea or vomiting & 9956 & $\begin{array}{l}\oplus \oplus \oplus \oplus \\
\mathrm{HIGH}\end{array}$ & $0.96(0.75-1.22)$ & 31 per 1000 & $\begin{array}{l}1 \text { fewer per } 1000 \text { ( } 8 \text { fewer to } 7 \\
\text { more) }\end{array}$ \\
\hline $\begin{array}{l}\text { Hypertension (celecoxib and } \\
\text { etoricoxib only) }\end{array}$ & 5280 & $\begin{array}{l}\oplus \oplus \oplus \oplus \\
\mathrm{HIGH}\end{array}$ & $1.21(0.80-1.83)$ & 28 per 1000 & $\begin{array}{l}6 \text { more per } 1000 \text { ( } 6 \text { fewer to } 23 \\
\text { more) }\end{array}$ \\
\hline $\begin{array}{l}\text { Central nervous system adverse } \\
\text { events }\end{array}$ & 14,649 & $\begin{array}{l}\oplus \oplus \oplus \oplus \\
\mathrm{HIGH}\end{array}$ & $0.94(0.84-1.04)$ & 87 per 1000 & $\begin{array}{l}5 \text { fewer per } 1000 \text { (14 fewer to } \\
3 \text { more) }\end{array}$ \\
\hline Rash or pruritus & 4248 & $\begin{array}{l}\oplus \oplus \oplus \oplus \\
\mathrm{HIGH}\end{array}$ & $1.02(0.76-1.37)$ & 36 per 1000 & $\begin{array}{l}1 \text { more per } 1000 \text { ( } 9 \text { fewer to } 13 \\
\text { more) }\end{array}$ \\
\hline
\end{tabular}

GRADE Working Group grades of evidence: High certainty we are very confident that the true effect lies close to that of the estimate of the effect; Moderate certainty we are moderately confident in the effect estimate: the true effect is likely to be close to the estimate of the effect, but there is a possibility that it is substantially different; Low certainty our confidence in the effect estimate is limited: the true effect may be substantially different from the estimate of the effect; Very low certainty we have very little confidence in the effect estimate: the true effect is likely to be substantially different from the estimate of effect

The risk in the intervention group (and its $95 \% \mathrm{CI}$ ) is based on the assumed risk in the comparison group and the relative effect of the intervention (and its $95 \% \mathrm{CI}$ )

CI confidence interval, $C O X-2$ cyclooxygenase-2

${ }^{a}$ Renal and hepatic events and death were not reported as outcomes in sufficient studies to analyze

${ }^{\mathrm{b}} \mathrm{I}^{2}$ between 50 and $75 \%(p<0.001)$

of the outcome. Our analysis was limited to studies in OA patients only; thus, safety issues could be missed in relevant subgroups such as in patients after coronary artery bypass graft surgery, or in patients with rheumatoid arthritis.

\section{Conclusions}

Along with non-selective NSAIDs, the use of COX-2 inhibitors in $\mathrm{OA}$ is associated with a significant increased risk of drug-related AEs compared with placebo. Specifically, we found an increased risk of upper-gastrointestinal AEs with COX-2 inhibitors, especially abdominal pain. We also found an increased risk of cardiovascular AEs with COX-2 inhibitors, namely hypertension, heart failure and edema. Our results confirm that a cautious approach to the use of NSAIDs and COX-2 inhibitors for the management of pain and inflammation in $\mathrm{OA}$ is advisable, with selection of treatment tailored to the individual patient characteristics. In OA patients at increased risk of gastrointestinal AEs, COX-2 inhibitors with the addition of a proton pump inhibitor may be used in preference to a non-selective NSAID; while for patients at increased risk of cardiovascular AEs, the use of COX-2 inhibitors should be avoided. Low-dose celecoxib $(200 \mathrm{mg} /$ day) may be the preferred NSAID due to its lower propensity for gastrointestinal and cardiovascular toxicity. To maximize the risk : benefit of NSAIDs, including COX-2 inhibitors, the European Society for Clinical and Economic Aspects of Osteoporosis, Osteoarthritis, and Musculoskeletal Diseases (ESCEO) recommends intermittent or longer cycles of NSAID use rather than chronic treatment in order to minimize safety concerns [68].

Acknowledgements This paper is written on behalf of the European Society for Clinical and Economic Aspects of Osteoporosis, Osteoarthritis and Musculoskeletal Diseases (ESCEO) Working Group on the safety of anti-osteoarthritis medications: Nasser Al-Daghri, Nigel Arden, Bernard Avouac, Olivier Bruyère, Roland Chapurlat, Philip Conaghan, Cyrus Cooper, Elizabeth Curtis, Elaine Dennison, Nicholas Fuggle, Gabriel Herrero-Beaumont, Germain Honvo, Margreet Kloppenburg, Stefania Maggi, Tim McAlindon, Alberto Migliore, Ouafa Mkinsi, François Rannou, Jean-Yves Reginster, René Rizzoli, Roland Roth, Thierry Thomas, Daniel Uebelhart and Nicola Veronese. The authors would like to express their most sincere gratitude to Dr Lisa Buttle for her invaluable help with the manuscript preparation. Dr Lisa Buttle was entirely funded by the ESCEO asbl, Belgium. 


\section{Compliance with Ethical Standards}

All authors meet the ICMJE criteria for authorship for this manuscript, take responsibility for the integrity of the work as a whole, and have given final approval to the version to be published.

Role of the funding source The Working Group was entirely funded by ESCEO, a Belgian not-for-profit organization. ESCEO receives unrestricted educational grants, to support its educational and scientific activities, from non-governmental organizations, not-for-profit organizations, non-commercial and corporate partners. The choice of topics, participants, content and agenda of the working groups as well as the writing, editing, submission and reviewing of the manuscript are under the sole responsibility of ESCEO, without any influence from third parties.

Conflict of interest $\mathrm{O}$. Bruyère reports grants from Biophytis, IBSA, MEDA, Servier, SMB and Theramex outside the submitted work. C. Cooper reports personal fees from Alliance for Better Bone Health, Amgen, Eli Lilly, GlaxoSmithKline, Medtronic, Merck, Novartis, Pfizer, Roche, Servier, Takeda and UCB outside of the submitted work. J-Y. Reginster reports grants from IBSA-Genevrier, Mylan, CNIEL, Radius Health (through institution); consulting fees from IBSA-Genevrier, Mylan, CNIEL, Radius Health, Pierre Fabre; fees for participation in review activities from IBSA-Genevrier, MYLAN, CNIEL, Radius Health, Teva; payment for lectures from AgNovos, CERIN, CNIEL, Dairy Research Council (DRC), Echolight, IBSA-Genevrier, Mylan, Pfizer Consumer Health, Teva, Theramex outside of the submitted work. E. Curtis reports lecture fees and travel support from Eli Lilly, Pfizer and UCB outside of the submitted work. N. Fuggle reports travel support from Eli Lilly and Pfizer outside of the submitted work. E. Dennison reports personal fees for lectures or advisory boards from UCB and Pfizer outside of the submitted work. N. Corp reports partial funding of employment at Keele University from Versus Arthritis (registered charity), and travel support from Versus Arthritis outside of the submitted work. S. Maggi reports research grants from Takeda, MSD, Pfizer, GSK and consulting fees or honorarium from MSD and Pfizer outside of the submitted work and outside of the research topic. G. Honvo, S. Shaw, L. Spooner, G. Ntani, C. Parsons and J. Baird report nothing to disclose.

Open Access This article is distributed under the terms of the Creative Commons Attribution-NonCommercial 4.0 International License (http://creativecommons.org/licenses/by-nc/4.0/), which permits any noncommercial use, distribution, and reproduction in any medium, provided you give appropriate credit to the original author(s) and the source, provide a link to the Creative Commons license, and indicate if changes were made.

\section{References}

1. Harirforoosh S, Asghar W, Jamali F. Adverse effects of nonsteroidal antiinflammatory drugs: an update of gastrointestinal, cardiovascular and renal complications. J Pharm Pharm Sci. 2013;16(5):821-47.

2. Donnelly MT, Hawkey CJ. Review article: COX-II inhibitorsa new generation of safer NSAIDs? Aliment Pharmacol Ther. 1997;11(2):227-36.

3. Bresalier RS, Sandler RS, Quan H, Bolognese JA, Oxenius B, Horgan K, et al. Cardiovascular events associated with rofecoxib in a colorectal adenoma chemoprevention trial. N Engl J Med. 2005;352(11):1092-102. https://doi.org/10.1056/NEJMoa050493.
4. Ott E, Nussmeier NA, Duke PC, Feneck RO, Alston RP, Snabes $\mathrm{MC}$, et al. Efficacy and safety of the cyclooxygenase 2 inhibitors parecoxib and valdecoxib in patients undergoing coronary artery bypass surgery. J Thorac Cardiovasc Surg. 2003;125(6):1481-92.

5. Nussmeier NA, Whelton AA, Brown MT, Langford RM, Hoeft A, Parlow JL, et al. Complications of the COX-2 inhibitors parecoxib and valdecoxib after cardiac surgery. N Engl J Med. 2005;352(11):1081-91. https://doi.org/10.1056/NEJMoa050330.

6. Pillans PI, Ghiculescu RA, Lampe G, Wilson R, Wong R, Macdonald GA. Severe acute liver injury associated with lumiracoxib. J Gastroenterol Hepatol. 2012;27(6):1102-5. https://doi.org/10.1 111/j.1440-1746.2011.07036.x.

7. Patrignani P, Tacconelli S, Bruno A, Sostres C, Lanas A. Managing the adverse effects of nonsteroidal anti-inflammatory drugs. Expert Rev Clin Pharmacol. 2011;4(5):605-21. https://doi. org/10.1586/ecp.11.36.

8. Yang M, Wang HT, Zhao M, Meng WB, Ou JQ, He JH, et al. Network meta-analysis comparing relatively selective COX-2 inhibitors versus coxibs for the prevention of NSAID-induced gastrointestinal injury. Medicine (Baltimore). 2015;94(40):e1592. https://doi.org/10.1097/MD.0000000000001592.

9. van Walsem A, Pandhi S, Nixon RM, Guyot P, Karabis A, Moore RA. Relative benefit-risk comparing diclofenac to other traditional non-steroidal anti-inflammatory drugs and cyclooxygenase-2 inhibitors in patients with osteoarthritis or rheumatoid arthritis: a network meta-analysis. Arthritis Res Ther. 2015;17:66. https:// doi.org/10.1186/s13075-015-0554-0.

10. Essex MN, Zhang RY, Berger MF, Upadhyay S, Park PW. Safety of celecoxib compared with placebo and non-selective NSAIDs: cumulative meta-analysis of 89 randomized controlled trials. Expert Opin Drug Saf. 2013;12(4):465-77. https://doi. org/10.1517/14740338.2013.780595.

11. Coxib and traditional NSAID Trialists' (CNT) Collaboration, Bhala N, Emberson J, Merhi A, Abramson S, Arber N, et al. Vascular and upper gastrointestinal effects of non-steroidal antiinflammatory drugs: meta-analyses of individual participant data from randomised trials. Lancet. 2013;382(9894):769-79. https:// doi.org/10.1016/s0140-6736(13)60900-9.

12. Trelle S, Reichenbach S, Wandel S, Hildebrand P, Tschannen B, Villiger PM, et al. Cardiovascular safety of non-steroidal anti-inflammatory drugs: network meta-analysis. BMJ. 2011;342:c7086. https://doi.org/10.1136/bmj.c7086.

13. Zhang J, Ding EL, Song Y. Adverse effects of cyclooxygenase 2 inhibitors on renal and arrhythmia events: meta-analysis of randomized trials. JAMA. 2006;296(13):1619-32. https://doi. org/10.1001/jama.296.13.jrv60015.

14. McGettigan P, Henry D. Cardiovascular risk and inhibition of cyclooxygenase: a systematic review of the observational studies of selective and nonselective inhibitors of cyclooxygenase 2. JAMA. 2006;296(13):1633-44. https://doi.org/10.1001/ jama.296.13.jrv60011.

15. Higgins JPT, Green S. Cochrane handbook for systematic reviews of interventions. Version 5.1.0 (updated March 2011). The Cochrane Collaboration. http://www.handbook.cochrane.org.

16. Moher D, Liberati A, Tetzlaff J, Altman DG, PRISMA Group. Preferred reporting items for systematic reviews and meta-analyses: the PRISMA statement. J Clin Epidemiol. 2009;62(10):1006-12. https://doi.org/10.1016/j.jclinepi.2009.06.005.

17. DerSimonian R, Laird N. Meta-analysis in clinical trials. Control Clin Trials. 1986;7(3):177-88.

18. Bradburn MJ, Deeks JJ, Berlin JA, Russell Localio A. Much ado about nothing: a comparison of the performance of meta-analytical methods with rare events. Stat Med. 2007;26(1):53-77. https ://doi.org/10.1002/sim.2528.

19. Stijnen T, Hamza TH, Ozdemir P. Random effects meta-analysis of event outcome in the framework of the generalized 
linear mixed model with applications in sparse data. Stat Med. 2010;29(29):3046-67. https://doi.org/10.1002/sim.4040.

20. Normand SL. Meta-analysis: formulating, evaluating, combining, and reporting. Stat Med. 1999;18(3):321-59.

21. Higgins JP, Thompson SG, Deeks JJ, Altman DG. Measuring inconsistency in meta-analyses. BMJ. 2003;327(7414):557-60. https://doi.org/10.1136/bmj.327.7414.557.

22. Guyatt G, Oxman AD, Akl EA, Kunz R, Vist G, Brozek J, et al. GRADE guidelines: 1 Introduction-GRADE evidence profiles and summary of findings tables. J Clin Epidemiol. 2011;64(4):383-94. https://doi.org/10.1016/j.jclinepi.2010.04.026.

23. GRADEpro GDT. GRADEpro Guideline Development Tool [Software]. McMaster University, 2015 (developed by Evidence Prime, Inc.). Evidence Prime, Inc. http://gradepro.org.

24. Bensen WG, Fiechtner JJ, McMillen JI, Zhao WW, Yu SS, Woods EM, et al. Treatment of osteoarthritis with celecoxib, a cyclooxygenase-2 inhibitor: a randomized controlled trial. Mayo Clin Proc. 1999;74(11):1095-105. https://doi.org/10.4065/74.11.1095.

25. Bingham CO 3rd, Sebba AI, Rubin BR, Ruoff GE, Kremer J, Bird S, et al. Efficacy and safety of etoricoxib $30 \mathrm{mg}$ and celecoxib 200 $\mathrm{mg}$ in the treatment of osteoarthritis in two identically designed, randomized, placebo-controlled, non-inferiority studies. Rheumatology (Oxford). 2007;46(3):496-507. https://doi.org/10.1093/ rheumatology/kel296.

26. Cannon CP, Chen C, Curtis SP, Viscusi J, Ahmed T, Dibattiste PM. A comparison of cardiovascular biomarkers in patients treated for three months with etoricoxib, celecoxib, ibuprofen, and placebo. Arch Drug Inf. 2008;1(1):4-13. https://doi.org/10.1 111/j.1753-5174.2007.00002.x.

27. Conaghan PG, Dickson J, Bolten W, Cevc G, Rother M. A multicentre, randomized, placebo- and active-controlled trial comparing the efficacy and safety of topical ketoprofen in Transfersome gel (IDEA-033) with ketoprofen-free vehicle (TDT 064) and oral celecoxib for knee pain associated with osteoarthritis. Rheumatology (Oxford). 2013;52(7):1303-12. https://doi.org/10.1093/rheum atology/ket133.

28. Cryer BL, Sostek MB, Fort JG, Svensson O, Hwang C, Hochberg MC. A fixed-dose combination of naproxen and esomeprazole magnesium has comparable upper gastrointestinal tolerability to celecoxib in patients with osteoarthritis of the knee: results from two randomized, parallel-group, placebo-controlled trials. Ann Med. 2011;43(8):594-605. https://doi.org/10.3109/07853 890.2011.625971.

29. Day R, Morrison B, Luza A, Castaneda O, Strusberg A, Nahir $\mathrm{M}$, et al. A randomized trial of the efficacy and tolerability of the COX-2 inhibitor rofecoxib vs ibuprofen in patients with osteoarthritis. Rofecoxib/Ibuprofen Comparator Study Group. Arch Intern Med. 2000;160(12):1781-7.

30. DeLemos BP, Xiang J, Benson C, Gana TJ, Pascual ML, Rosanna R, et al. Tramadol hydrochloride extended-release once-daily in the treatment of osteoarthritis of the knee and/or hip: a double-blind, randomized, dose-ranging trial. Am J Ther. 2011;18(3):216-26. https://doi.org/10.1097/MJT.0b013e3181 cec307.

31. Ehrich EW, Schnitzer TJ, McIlwain H, Levy R, Wolfe F, Weisman $\mathrm{M}$, et al. Effect of specific COX-2 inhibition in osteoarthritis of the knee: a 6 week double blind, placebo controlled pilot study of rofecoxib. Rofecoxib Osteoarthritis Pilot Study Group. J Rheumatol. 1999;26(11):2438-47.

32. Essex MN, O'Connell M, Bhadra Brown P. Response to nonsteroidal anti-inflammatory drugs in African Americans with osteoarthritis of the knee. J Int Med Res. 2012;40(6):2251-66. https:// doi.org/10.1177/030006051204000623.

33. Essex MN, Behar R, O'Connell MA, Brown PB. Efficacy and tolerability of celecoxib and naproxen versus placebo in Hispanic patients with knee osteoarthritis. Int J Gen Med. 2014;7:227-35. https://doi.org/10.2147/ijgm.s61297.

34. Essex MN, O'Connell MA, Behar R, Bao W. Efficacy and safety of nonsteroidal anti-inflammatory drugs in Asian patients with knee osteoarthritis: summary of a randomized, placebo-controlled study. Int J Rheum Dis. 2016;19(3):262-70. https://doi. org/10.1111/1756-185x.12667.

35. Fleischmann R, Sheldon E, Maldonado-Cocco J, Dutta D, Yu S, Sloan VS. Lumiracoxib is effective in the treatment of osteoarthritis of the knee: a prospective randomized 13-week study versus placebo and celecoxib. Clin Rheumatol. 2006;25(1):42-53. https ://doi.org/10.1007/s10067-005-1126-5.

36. Ghosh S, Paul S, Das N, Bhattacharyya TK. A study on the effects of diclofenac sodium and etoricoxib in the treatment of osteoarthritis. J Indian Med Assoc. 2007;105(5):260-2.

37. Gordo AC, Walker C, Armada B, Zhou D. Efficacy of celecoxib versus ibuprofen for the treatment of patients with osteoarthritis of the knee: a randomized double-blind, non-inferiority trial. J Int Med Res. 2017;45(1):59-74. https://doi.org/10.1177/0300060516 673707.

38. Gottesdiener K, Schnitzer T, Fisher C, Bockow B, Markenson J, Ko A, et al. Results of a randomized, dose-ranging trial of etoricoxib in patients with osteoarthritis. Rheumatology (Oxford). 2002;41(9):1052-61.

39. Karlsson J, Pivodic A, Aguirre D, Schnitzer TJ. Efficacy, safety, and tolerability of the cyclooxygenase-inhibiting nitric oxide donator naproxcinod in treating osteoarthritis of the hip or knee. J Rheumatol. 2009;36(6):1290-7. https://doi.org/10.3899/jrheu m.081011.

40. Kivitz AJ, Moskowitz RW, Woods E, Hubbard RC, Verburg KM, Lefkowith JB, et al. Comparative efficacy and safety of celecoxib and naproxen in the treatment of osteoarthritis of the hip. J Int Med Res. 2001;29(6):467-79. https://doi.org/10.1177/14732 3000102900602.

41. Laine L, Harper S, Simon T, Bath R, Johanson J, Schwartz H, et al. A randomized trial comparing the effect of rofecoxib, a cyclooxygenase 2 -specific inhibitor, with that of ibuprofen on the gastroduodenal mucosa of patients with osteoarthritis. Rofecoxib Osteoarthritis Endoscopy Study Group. Gastroenterology. 1999;117(4):776-83.

42. Lehmann R, Brzosko M, Kopsa P, Nischik R, Kreisse A, Thurston $\mathrm{H}$, et al. Efficacy and tolerability of lumiracoxib $100 \mathrm{mg}$ once daily in knee osteoarthritis: a 13-week, randomized, double-blind study vs. placebo and celecoxib. Curr Med Res Opin. 2005;21(4):517-26. https://doi.org/10.1185/030079905x38196.

43. Leung AT, Malmstrom K, Gallacher AE, Sarembock B, Poor G, Beaulieu A, et al. Efficacy and tolerability profile of etoricoxib in patients with osteoarthritis: a randomized, double-blind, placebo and active-comparator controlled 12-week efficacy trial. Curr Med Res Opin. 2002;18(2):49-58. https://doi.org/10.1185/0300799021 25000282.

44. McKenna F, Borenstein D, Wendt H, Wallemark C, Lefkowith $\mathrm{JB}$, Geis GS. Celecoxib versus diclofenac in the management of osteoarthritis of the knee. Scand J Rheumatol. 2001;30(1):11-8.

45. Puopolo A, Boice JA, Fidelholtz JL, Littlejohn TW, Miranda P, Berrocal A, et al. A randomized placebo-controlled trial comparing the efficacy of etoricoxib $30 \mathrm{mg}$ and ibuprofen $2400 \mathrm{mg}$ for the treatment of patients with osteoarthritis. Osteoarthr Cartil. 2007;15(12):1348-56. https://doi.org/10.1016/j.joca.2007.05.022.

46. Reginster JY, Malmstrom K, Mehta A, Bergman G, Ko AT, Curtis SP, et al. Evaluation of the efficacy and safety of etoricoxib compared with naproxen in two, 138-week randomised studies of patients with osteoarthritis. Ann Rheum Dis. 2007;66(7):945-51. https://doi.org/10.1136/ard.2006.059162.

47. Rother M, Lavins BJ, Kneer W, Lehnhardt K, Seidel EJ, Mazgareanu S. Efficacy and safety of epicutaneous ketoprofen in 
Transfersome (IDEA-033) versus oral celecoxib and placebo in osteoarthritis of the knee: multicentre randomised controlled trial. Ann Rheum Dis. 2007;66(9):1178-83. https://doi.org/10.1136/ ard.2006.065128.

48. Saag K, van der Heijde D, Fisher C, Samara A, DeTora L, Bolognese J, et al. Rofecoxib, a new cyclooxygenase 2 inhibitor, shows sustained efficacy, comparable with other nonsteroidal anti-inflammatory drugs: a 6-week and a 1-year trial in patients with osteoarthritis. Osteoarthritis Studies Group. Arch Fam Med. 2000;9(10):1124-34.

49. Sawitzke AD, Shi H, Finco MF, Dunlop DD, Harris CL, Singer NG, et al. Clinical efficacy and safety of glucosamine, chondroitin sulphate, their combination, celecoxib or placebo taken to treat osteoarthritis of the knee: 2-year results from GAIT. Ann Rheum Dis. 2010;69(8):1459-64. https://doi.org/10.1136/ard.2009.12046 9.

50. Schnitzer TJ, Kivitz AJ, Lipetz RS, Sanders N, Hee A. Comparison of the COX-inhibiting nitric oxide donator AZD3582 and rofecoxib in treating the signs and symptoms of Osteoarthritis of the knee. Arthritis Rheumatol. 2005;53(6):827-37. https://doi. org/10.1002/art.21586.

51. Schnitzer TJ, Dattani ID, Seriolo B, Schneider H, Moore A, Tseng L, et al. A 13-week, multicenter, randomized, doubleblind study of lumiracoxib in hip osteoarthritis. Clin Rheumatol. 2011;30(11):1433-46. https://doi.org/10.1007/s1006 7-011-1776-4.

52. Sheldon E, Beaulieu A, Paster Z, Dutta D, Yu S, Sloan VS. Efficacy and tolerability of lumiracoxib in the treatment of osteoarthritis of the knee: a 13-week, randomized, double-blind comparison with celecoxib and placebo. Clin Ther. 2005;27(1):64-77. https://doi.org/10.1016/j.clinthera.2005.01.002.

53. Smugar SS, Schnitzer TJ, Weaver AL, Rubin BR, Polis AB, Tershakovec AM. Rofecoxib $12.5 \mathrm{mg}$, rofecoxib $25 \mathrm{mg}$, and celecoxib $200 \mathrm{mg}$ in the treatment of symptomatic osteoarthritis: results of two similarly designed studies. Curr Med Res Opin. 2006;22(7):1353-67. https://doi.org/10.1185/030079906x10487 6.

54. Tannenbaum H, Berenbaum F, Reginster JY, Zacher J, Robinson J, Poor G, et al. Lumiracoxib is effective in the treatment of osteoarthritis of the knee: a 13 week, randomised, double blind study versus placebo and celecoxib. Ann Rheum Dis. 2004;63(11):141926. https://doi.org/10.1136/ard.2003.015974.

55. Truitt KE, Sperling RS, Ettinger WH Jr, Greenwald M, DeTora L, Zeng Q, et al. A multicenter, randomized, controlled trial to evaluate the safety profile, tolerability, and efficacy of rofecoxib in advanced elderly patients with osteoarthritis. Aging (Milano). 2001;13(2):112-21.

56. Weaver AL, Messner RP, Storms WW, Polis AB, Najarian DK, Petruschke RA, et al. Treatment of patients with osteoarthritis with rofecoxib compared with nabumetone. J Clin Rheumatol. 2006;12(1):17-25. https://doi.org/10.1097/01.rhu.0000200384 .79405 .33 .

57. Wiesenhutter CW, Boice JA, Ko A, Sheldon EA, Murphy FT, Wittmer BA, et al. Evaluation of the comparative efficacy of etoricoxib and ibuprofen for treatment of patients with osteoarthritis: a randomized, double-blind, placebo-controlled trial. Mayo Clin Proc. 2005;80(4):470-9.
58. Williams GW, Ettlinger RE, Ruderman EM, Hubbard RC, Lonien ME, Yu SS, et al. Treatment of osteoarthritis with a once-daily dosing regimen of celecoxib: a randomized, controlled trial. J Clin Rheumatol. 2000;6(2):65-74.

59. Mallen SR, Essex MN, Zhang R. Gastrointestinal tolerability of NSAIDs in elderly patients: a pooled analysis of 21 randomized clinical trials with celecoxib and nonselective NSAIDs. Curr Med Res Opin. 2011;27(7):1359-66. https://doi.org/10.1185/03007 995.2011.581274.

60. Sudano I, Flammer AJ, Roas S, Enseleit F, Noll G, Ruschitzka F. Nonsteroidal antiinflammatory drugs, acetaminophen, and hypertension. Curr Hypertens Rep. 2012;14(4):304-9. https:// doi.org/10.1007/s11906-012-0274-7.

61. Sowers JR, White WB, Pitt B, Whelton A, Simon LS, Winer N, et al. The Effects of cyclooxygenase-2 inhibitors and nonsteroidal anti-inflammatory therapy on 24-hour blood pressure in patients with hypertension, osteoarthritis, and type 2 diabetes mellitus. Arch Intern Med. 2005;165(2):161-8. https://doi.org/10.1001/ archinte.165.2.161.

62. Lewington S, Clarke R, Qizilbash N, Peto R, Collins R, Prospective Studies C. Age-specific relevance of usual blood pressure to vascular mortality: a meta-analysis of individual data for one million adults in 61 prospective studies. Lancet. 2002;360(9349):1903-13.

63. Ungprasert P, Srivali N, Thongprayoon C. Nonsteroidal antiinflammatory drugs and risk of incident heart failure: a systematic review and meta-analysis of observational studies. Clin Cardiol. 2016;39(2):111-8. https://doi.org/10.1002/clc.22502.

64. Mamdani M, Juurlink DN, Lee DS, Rochon PA, Kopp A, Naglie $\mathrm{G}$, et al. Cyclo-oxygenase-2 inhibitors versus non-selective nonsteroidal anti-inflammatory drugs and congestive heart failure outcomes in elderly patients: a population-based cohort study. Lancet. 2004;363(9423):1751-6. https://doi.org/10.1016/S0140 $-6736(04) 16299-5$.

65. Nissen SE, Yeomans ND, Solomon DH, Luscher TF, Libby P, Husni ME, et al. Cardiovascular safety of celecoxib, naproxen, or ibuprofen for arthritis. N Engl J Med. 2016;375(26):2519-29. https://doi.org/10.1056/NEJMoa1611593.

66. Solomon DH, Husni ME, Wolski KE, Wisniewski LM, Borer JS, Graham DY, et al. Differences in safety of nonsteroidal antiinflammatory drugs in patients with osteoarthritis and patients with rheumatoid arthritis: a randomized clinical trial. Arthritis Rheumatol. 2018;70(4):537-46. https://doi.org/10.1002/art.40400.

67. Hirayama A, Tanahashi N, Daida H, Ishiguro N, Chachin M, Sugioka $\mathrm{T}$, et al. Assessing the cardiovascular risk between celecoxib and nonselective nonsteroidal antiinflammatory drugs in patients with rheumatoid arthritis and osteoarthritis. Circ J. 2014;78(1):194-205.

68. Bruyere O, Cooper C, Pelletier JP, Branco J, Brandi ML, Guillemin F, et al. An algorithm recommendation for the management of knee osteoarthritis in Europe and internationally: a report from a task force of the European Society for Clinical and Economic Aspects of Osteoporosis and Osteoarthritis (ESCEO). Semin Arthritis Rheum. 2014;44(3):253-63. https://doi.org/10.1016/j. semarthrit.2014.05.014. 


\title{
Affiliations
}

\section{Elizabeth Curtis ${ }^{1}$ (1) - Nicholas Fuggle ${ }^{1}$. Sarah Shaw ${ }^{1} \cdot$ Laura Spooner $^{2} \cdot$ Georgia Ntani $^{1}$. Camille Parsons ${ }^{1}$. Nadia Corp ${ }^{3}$. Germain Honvo ${ }^{4,5}$. Janis Baird ${ }^{1}$. Stefania Maggi ${ }^{6}$. Elaine Dennison ${ }^{1}$. Olivier Bruyère ${ }^{4,5}$. Jean-Yves Reginster ${ }^{4,5,7}$ (D) Cyrus Cooper ${ }^{1,5,8} \mathbb{B}_{\mathbb{C}}$}

\author{
Elizabeth Curtis \\ bc@mrc.soton.ac.uk \\ Nicholas Fuggle \\ nrf@mrc.soton.ac.uk \\ Sarah Shaw \\ ss@mrc.soton.ac.uk \\ Laura Spooner \\ laura.j.spooner@gmail.com \\ Georgia Ntani \\ gn@mrc.soton.ac.uk \\ Camille Parsons \\ cp@mrc.soton.ac.uk \\ Nadia Corp \\ n.corp@keele.ac.uk \\ Germain Honvo \\ germain.honvo@uliege.be \\ Janis Baird \\ jb@mrc.soton.ac.uk \\ Stefania Maggi \\ stefania.maggi@in.cnr.it \\ Elaine Dennison \\ emd@mrc.soton.ac.uk \\ Olivier Bruyère \\ olivier.bruyere@uliege.be
}

Jean-Yves Reginster

jyreginster@uliege.be

1 MRC Lifecourse Epidemiology Unit, University of Southampton, Southampton General Hospital, Tremona Road, Southampton SO16 6YD, UK

2 Portsmouth Hospitals NHS Trust, Portsmouth, UK

3 Arthritis Research UK Primary Care Centre, Institute for Primary Care and Health Sciences, Keele University, Keele, UK

4 Department of Public Health, Epidemiology and Health Economics, University of Liège, Liège, Belgium

5 WHO Collaborating Centre for Public Heath Aspects of Musculoskeletal Health and Aging, Liège, Belgium

6 Aging Program, National Research Council, Neuroscience Institute, Padua, Italy

7 Chair for Biomarkers of Chronic Diseases, Biochemistry Department, College of Science, King Saud University, Riyadh, Kingdom of Saudi Arabia

8 National Institute for Health Research (NIHR) Musculoskeletal Biomedical Research Unit, University of Oxford, Oxford, UK 